\title{
Health-related quality of life in primary hepatic cancer: a systematic review assessing the methodological properties of instruments and a meta-analysis comparing treatment strategies
}

\author{
Kerstin Wohlleber $^{1} \cdot$ Patrick Heger $^{1,2} \cdot$ Pascal Probst $^{1,2} \cdot$ Christoph Engel $^{3} \cdot$ Markus K. Diener $^{1,2}$. \\ André L. Mihaljevic ${ }^{1,2}$ (1)
}

Accepted: 23 February 2021 / Published online: 20 July 2021

(C) The Author(s) 2021

\begin{abstract}
Purpose Patient-reported outcomes including health-related quality of life (HRQoL) are important oncological outcome measures. The validation of HRQoL instruments for patients with hepatocellular and cholangiocellular carcinoma is lacking. Furthermore, studies comparing different treatment options in respect to HRQoL are sparse. The objective of the systematic review and meta-analysis was, therefore, to identify all available HRQoL tools regarding primary liver cancer, to assess the methodological quality of these HRQoL instruments and to compare surgical, interventional and medical treatments with regard to HRQoL.

Methods A systematic literature search was conducted in MEDLINE, the Cochrane library, PsycINFO, CINAHL and EMBASE. The methodological quality of all identified HRQoL instruments was performed according to the COnsensusbased Standards for the selection of health status Measurements INstruments (COSMIN) standard. Consequently, the quality of reporting of HRQoL data was assessed. Finally, wherever possible HRQoL data were extracted and quantitative analyses were performed.

Results A total of 124 studies using 29 different HRQoL instruments were identified. After the methodological assessment, only 10 instruments fulfilled the psychometric criteria and could be included in subsequent analyses. However, quality of reporting of HRQoL data was insufficient, precluding meta-analyses for 9 instruments.

Conclusion Using a standardized methodological assessment, specific HRQoL instruments are recommended for use in patients with hepatocellular and cholangiocellular carcinoma. HRQoL data of patients undergoing treatment of primary liver cancers are sparse and reporting falls short of published standards. Meaningful comparison of established treatment options with regard to HRQoL was impossible indicating the need for future research.
\end{abstract}

Keywords Quality of life $\cdot$ Health-related quality of life $\cdot$ Hepatocellular carcinoma $\cdot$ Cholangiocellular carcinoma

André L. Mihaljevic

andre.mihaljevic@uni-ulm.de

1 Department of General, Visceral and Transplant Surgery, University of Heidelberg, Im Neuenheimer Feld 110, 69120 Heidelberg, Germany

2 The Study Centre of the German Surgical Society (SDGC), University of Heidelberg, Im Neuenheimer Feld 110, 69120 Heidelberg, Germany

3 Institute for Medical Informatics, Statistics and Epidemiology (IMISE), University of Leipzig, Härtelstraße 16-18, 04107 Leipzig, Germany

\section{Introduction}

Besides survival and treatment-associated adverse events, patient-reported outcomes (PROs) are arguably the most relevant outcome parameters in oncology. A PRO is defined as 'any outcome evaluated directly by the patient himself or herself and is based on patient's perception of a disease and its treatment(s)' [1]. PROs have many potential advantages as they may elucidate the relationship between clinical endpoints and the patient's well-being [1], allowing for a more comprehensive evaluation of patients' health [2].

Health-related quality of life (HRQoL) is a multidimensional PRO measure that is of special interest in oncology as it provides a 'personal assessment of the burden and impact 
of a malignant disease and its treatment,' [1] thus, adding valuable information for a true risk-benefit assessment. This is of special interest when prognosis is limited as in primary malignancies of the liver. HRQoL tools can be distinguished into generic, cancer-specific, cancer-type-specific and utility-(preference-)based instruments [3]. While definitions, implementation, evaluation and analyses of survival and toxicity/complication endpoints have been well standardized over the last decades, PROs are still under-evaluated and reported in most clinical settings. Multiple studies have aimed to define suitable HRQoL tools for different clinical settings, e.g. [4, 5], including cancer patients [6-8].

Hepatocellular carcinoma (HCC) and intrahepatic cholangiocarcinoma (CCA) account for more than $95 \%$ of all primary malignant liver tumours. Hepatitis $\mathrm{B}$ and $\mathrm{C}$ infections are the most prominent risk factor for HCC [9]. More than 840.000 patients were newly diagnosed with HCC or CCA in 2018, and numbers are estimated to rise $>1.3$ million annually until 2040 [10]. Although age-standardized incidence rates are moderate in the Western World, they are high in most parts of Asia and parts of West Africa [10], making HCC one of the most frequent tumours in these parts of the world. Prognosis is dismal with 5-year overall survival being around $15 \%$ in the USA and 5\% in low-income countries [9]. Besides surgical resection, medical treatment (e.g. chemotherapy, kinase inhibitors) and interventional treatments like radiofrequency ablation (RFA) and transarterial chemoembolization (TACE) constitute the three mainstays of treatment for both HCC and CCA.

Therefore, the objectives of this systematic review and meta-analysis were threefold: (1) to perform a systematic review to identify all published $\mathrm{HRQ}$ oL tools for primary liver cancer (HCC/CCA); (2) to assess the methodological quality and clinical relevance of these HRQoL measures; and (3) to synthesize quantitative data via means of a metaanalysis to compare surgery vs. interventional treatments vs. systemic therapies with regard to HRQoL.

\section{Material and methods}

This systematic review and meta-analysis is reported in line with current PRISMA guidelines [11]. The study was registered in the PROSPERO database on 18th July 2017 (registration number CRD42017068103).

\section{Eligibility criteria}

Studies investigating HRQoL in HCC or CCA patients were included independent of language or year of publication. All types of studies were included in our search with the exception of case reports, i.e. randomized controlled trials (RCT), cohort-type studies (CTS), case-control studies
(CCS) and cross-sectional studies. Furthermore, studies in animals (non-human studies) were excluded. The patient (P) and outcome (O) terms of the PICOT (patient-intervention-comparison-outcome-time) scheme were used to build a search strategy. The search used the 'outcome' term to identify PROMs describing quality of life or HRQoL and the 'patient' term to find studies including patients with HCC or CCA. Supplement 1 shows the search strategy for MEDLINE performed via OvidSP. If studies included mixed patient populations (e.g. including HCC patients together with metastatic cancer patients and other tumours), only those trials were included in which HRQoL data could clearly be extracted for HCC and CCA patients.

\section{Information sources}

The following databases were searched [12]: (a) MEDLINE via OvidSP last searched on 18th July 2019; (b) Ovid MEDLINE In-Process \& Other Non-Indexed Citations via OvidSP last searched on 18th July 2019; (c) the Cochrane library (including Cochrane reviews, other reviews, trials, technology assessments and economic evaluations) via the Cochrane homepage (Wiley online library) last searched on 18th July 2019; (d) PsycINFO via EBSCO host last searched on 18th July 2019; (e) CINAHL via EBSCO host last searched on 18th July 2019 and (f) Excerpta Medica Database (EMBASE) via EMBASE homepage last searched on 18th July 2019. The references of the included articles were hand searched to identify additional relevant studies. Where necessary, authors were directly contacted to retrieve missing information.

\section{Search}

Sensitive search strategies were developed for all databases using wildcards and adjacency terms where appropriate. Supplement 1 shows the search strategy for MEDLINE performed via OvidSP. The search strategies for the other databases were adapted to the specific vocabulary of each database.

\section{Study selection}

Search results were imported into EndNote software (EndNote X7.7, Thomson Reuters) [13], and duplicates were removed by using the automated duplicate removal function of EndNote. Consequently, titles and abstracts of studies were screened by two authors (KW, ALM) for fulfilment of inclusion and exclusion criteria. Remaining duplicates were removed manually. For the remaining studies, full text articles were obtained, which were then screened for eligibility by two authors independently (KW, ALM). Reasons for exclusion of full text 
Fig. 1 Flow chart of included studies

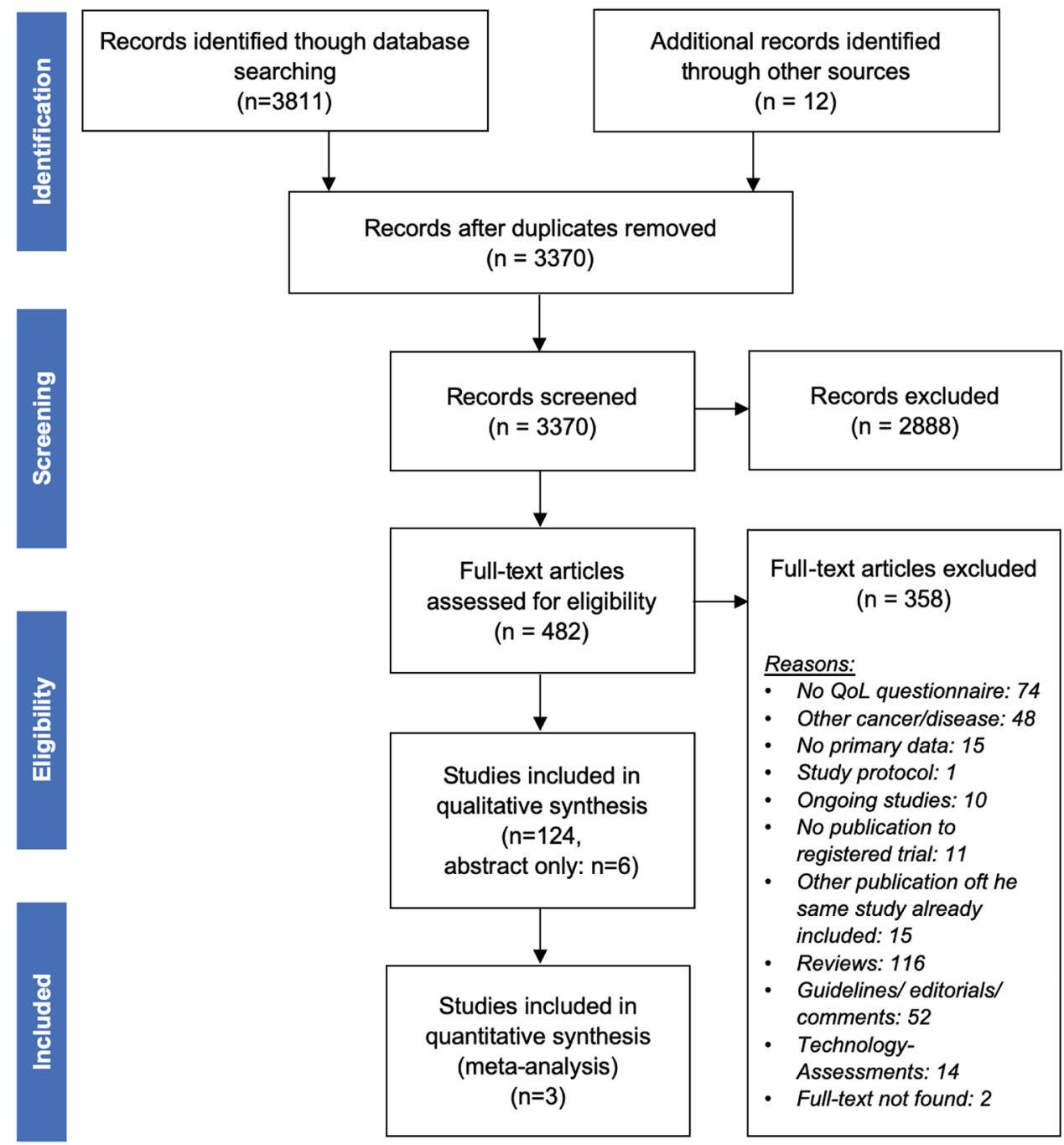

articles were recorded (Fig. 1). All remaining articles were included in the qualitative syntheses (objectives 1 and 2). For objective 3 (quantitative assessment), all articles using adequate HRQoL measures (i.e. fulfilling objective 2) were included in the assessment of quality of reporting of HRQoL data and risk of bias assessment of individual studies. HRQoL data were extracted wherever possible and grouped according to the three clinical settings: (a) surgery; (b) interventional therapy and (c) medical treatment.

HRQoL assessments were then grouped into 3-month periods. In a next step, quantitative data analysis was performed for those HRQoL measures for which $\geq 2$ quantitative data time points were available. For quantitative data analysis, results of individual studies were entered in RevMan 5 software 5.3. (Review Manager, Version 5.3 Copenhagen: The Nordic Cochrane Center, The Cochrane Collaboration, 2014).

\section{Data collection process}

Data were extracted by two authors independently (KW, ALM) and collected on pre-specified piloted forms. In case, required data were not reported in the study, and authors were contacted to obtain remaining data. Differences in data extraction were resolved by consensus with a third author (MKD).

\section{Data items}

The following data items were collected: title, author, year of publication, country where study was performed, journal, language, cancer type, intervention, control, co-interventions, primary endpoint, secondary endpoints, HRQoL tool used, type of study, number of centres, start and end dates of study and intervention, number of patients (total), number of patients allocated to intervention(s), number of 
patients allocated to control, number of patients evaluated for HRQoL (at each point in time), number of withdrawals, exclusions, conversions, duration of follow-up, HRQoL data at baseline and during follow-up, analysis strategy, subgroups measured and subgroups reported. Furthermore, the following baseline characteristics of patients (for both intervention and control group) were recorded: age, gender, severity of illness, co-morbidities and other relevant baseline characteristics.

\section{Evaluation of methodological quality of the HRQoL measures}

The methodological quality of HRQoL measures was assessed based on specific psychometric criteria. Owing to the lack of uniform consensus on how to appraise PRO measures, criteria were applied based on published recommendations $[3,14]$ in accordance with U.S. Food and Drug Administration guidance [15] and the Oxford University PROMs Group guidelines and the COnsensus-based Standards for the selection of health status Measurements INstruments (COSMIN) [16]. The criteria and benchmarks laid out in Table 1 were used for evaluation and have been used in previous publications [4, 5]. A rating scale described in previous publications was applied to allocate a mark for each domain $[4,5]: 0$ no evidence reported;evidence not in favour; + evidence in favour; \pm conflicting evidence. Lack of basic psychometric evaluation was defined by a priori consensus as evaluation of less than 2 positive $(+)$ aspects (other than feasibility and interpretability) in HCC/CCA patients. Evaluation was limited to primary hepatic cancers (HCC/CCA), i.e. the psychometric properties of some instruments might have been evaluated in other types of cancer, but not in HCC/CCA patients. In case of lack of psychometric data for a given instrument, searches were conducted in Medline to identify additional studies that have evaluated the psychometric properties of the HRQoL instrument in closely related patient cohorts (e.g. patients with chronic liver disease).

\section{Evaluation of the quality of reporting of HRQOL data}

For assessment of reporting, the studies were analysed using the following questions: (a) Is HRQoL data analysis described in methods section? (b) Has an a priori statistical analysis plan for HRQoL outcomes been implemented, addressing common problems like missing data, multiple testing? (c) Is HRQoL raw data presented? (d) Is individual patient data reported? (e) Which summary scores are used for HRQoL data? (f) Which time points of HRQoL assessment are described in the methods section? g.) For which time points is HRQoL data reported in the results section?

Table 1 Psychometric criteria used to assess the quality of the patient-reported outcome measures

\begin{tabular}{|c|c|}
\hline Domain & Criteria \\
\hline est-retest reliability & $\begin{array}{l}\text { Test-retest: the intraclass correlation/weighted } \kappa \text { score should be } \geq 0.70 \text { for group comparisons and } \geq 0.90 \text { if scores are } \\
\text { going to be used for decisions about an individual based on their score. The mean difference (paired } t \text { test or Wilcoxon } \\
\text { signed-rank test) between time points } 1 \text { and } 2 \text {, and the } 95 \% \text { CI should also be reported }\end{array}$ \\
\hline Internal consistency & $\begin{array}{l}\text { A Cronbach's } \alpha \text { score of } \geq 0.70 \text { is considered good, and it should not exceed } \geq 0.92 \text { for group comparisons as this is taken } \\
\text { to indicate that items in the scale could be redundant. Item correlations should be } \geq 0.20\end{array}$ \\
\hline Content validity & $\begin{array}{l}\text { This is assessed qualitatively during the development of an instrument. To achieve good content validity, there must be } \\
\text { evidence that the instrument has been developed by consulting patients and experts as well as undertaking a literature } \\
\text { review. Patients should be involved in the development stage and item generation. The opinion of patient representa- } \\
\text { tives should be sought on the constructed scale }\end{array}$ \\
\hline Construct validity & $\begin{array}{l}\text { A correlation coefficient of } \geq 0.60 \text { is taken as strong evidence of construct validity. Authors should make specific direc- } \\
\text { tional hypotheses and estimate the strength of correlation before testing }\end{array}$ \\
\hline Criterion validity & A good argument should be made as to why an instrument is standard and correlation with the standard should be $\geq 0.70$ \\
\hline Responsiveness & $\begin{array}{l}\text { There are a number of methods to measure responsiveness, including t tests, effect size, standardized response means or } \\
\text { Guyatt's responsiveness index. There should be statistically significant changes in score of an expected magnitude }\end{array}$ \\
\hline Appropriateness & $\begin{array}{l}\text { Assessment whether the content of the instrument is appropriate to the questions which the clinical trial is intended to } \\
\text { address }\end{array}$ \\
\hline Interpretability & Subjective assessment whether the scores of the instrument are interpretable for patients or physicians \\
\hline Acceptability & Acceptability is measured by the completeness of the data supplied; $\geq 80 \%$ of the data should be complete \\
\hline Feasibility & Qualitative assessment whether the instrument is easy to administer and process \\
\hline Floor-Ceiling effect & $\begin{array}{l}\text { A floor or ceiling effect is considered if } 15 \% \text { of respondents are achieving the lowest or the highest score on the Instru- } \\
\text { ment }\end{array}$ \\
\hline
\end{tabular}

Adapted from $[4,5]$ 


\section{Assessment of risk of bias in individual studies}

For RCTs risk of bias was judged using The Cochrane Collaboration tool of for assessing quality and risk of bias [17]. Risk of bias for non-randomized, interventional trials was assessed with the ROBINS-I tool (Risk Of Bias In Nonrandomized Studies - of Interventions, formerly known as ACROBAT-NRSI) as recommended by the Cochrane collaboration [11]. Non-randomized, non-interventional studies were assessed using the Newcastle-Ottawa risk of bias tool [18], and cross-sectional studies were assessed using the AHRQ checklist. RCTs were judged to be at an overall high risk of bias if there was a serious risk of bias in any of the following domains: random sequence generation, allocation concealment, missing data. For non-randomized trials, the following overall risk of bias judgement for individual studies was used in line with Cochrane recommendations [11]: (a) low risk of bias: the study is judged to be at low risk of bias for all domains; (b) moderate risk of bias: the study is judged to be at low or moderate risk of bias for all domains; (c) serious risk of bias: the study is judged to be at serious risk of bias in at least one domain, but not at critical risk of bias in any domain; (d) Critical risk of bias: the study is judged to be at critical risk of bias in at least one domain.

\section{Statistical analysis}

Data were entered in RevMan 5 software 5.3. (Review Manager, Version 5.3 Copenhagen: The Nordic Cochrane Center, The Cochrane Collaboration, 2014) [19]. As level of significance, an alpha of 0.05 was determined. A random-effect model (inverse variance) was used as there has been clinical heterogeneity between the included trials. Heterogeneity was evaluated using $\mathrm{I}^{2}$ statistic. Results lower than $25 \%$ were considered as low, between $25 \%$ and $75 \%$ as possibly moderate, and results of $\mathrm{I}^{2}$ over $60 \%$ were considered as a considerable heterogeneity. HRQoL in HCC/CCA patients was compared by meta-analysis for the following types of interventions: (a) surgery; (b) interventional therapies (e.g. TACE, RFA) and (c) systemic therapies (e.g. chemotherapy). Only studies using the FACT-G/FACT-Hep could be used for meta-analysis (see results section). As these subscores are continuous variables, the mean difference in the FACTG/FACT-Hep subscores was used as effect measure.

\section{Results}

\section{Study selection}

We identified 3811 studies by database search and 12 additional studies by hand search resulting in a total of 3823 records. 453 of those studies were duplicates (Fig. 1). After screening titles and abstracts, the other 2888 records were excluded according to inclusion and exclusion criteria. Subsequently, the other 358 articles were excluded after full text analyses for the following reasons: no HRQoL tool $(n=74)$, other type of cancer (no HCC/CCA) $(n=48)$, no primary data $(n=198)$, ongoing study without report $(n=21)$, double publication $(n=15)$ and no full text available $(n=2)$. The remaining 124 studies were included in the final qualitative syntheses (Fig. 1).

\section{Study characteristics}

The characteristics of the 124 included studies are listed in Table 2 [20-140]. Most studies were cohort-type studies ( $n=50 ; 40.3 \%)$, either with $(n=12 ; 24 \%)$ or without control group $(n=38 ; 76 \%)$. The remaining studies were RCTs $(n=41 ; 33.1 \%)$, non-randomized controlled trials $(n=18$; $14.5 \%)$, cross-sectional studies $(n=7 ; 5.6 \%)$ or case-control studies $(n=8 ; 6.5 \%)$ (Supplement 2). A total of 21,496 patients were included in all studies. Frequently studies investigated HCC patients only (Supplement 2). Most studies were single-centre studies ( $n=83 ; 66.9 \%$; supplement 2 ). The country of origin is depicted in Supplement 2.

\section{Health-related quality of life instruments}

In total, 29 different HRQoLs in 124 studies instruments were identified by our search (Figs. 2 and 3). Of those, 26 different HRQoL PROMs were identified in HCC patients, 8 in CCA patients and 4 different tools in mixed patient cohorts. Multiple studies used more than one HRQoL tool (Table 1). The identified instruments covered all types of HRQoL (generic, cancer-specific, cancer-type-specific and utility-based HRQoL instruments) (Fig. 2).

Despite being labelled as HRQoL instruments in the studies, a number of the identified instruments solely address cancer symptoms and, thus, lack the multidimensionality that is requested for HRQoL and were, thus, excluded from further analyses (Fig. 3 step 1). These were (a) MD Anderson symptom inventory; (b) ESAS: Edmonton symptom assessment scale; (c) MD Anderson symptom inventory - gastrointestinal and (d) FHSI-8 FACT hepatobiliary symptom index. The remaining 25 instruments (117 studies) were included in the further analyses (Fig. 3). These 25 instruments use two to eight domains covering various aspects of quality of life (e.g. physical and mental health, role functioning and symptom burden). The EORTC QLQ-C30 and the FACT-G have cancer-type-specific supplements (EORTC QLQ-HCC18 and FACT-Hep) which can only be used in combination with the more general questionnaire. The questionnaires comprise 5 (EQ-5D) to 47 questions (NIDDK$\mathrm{QA})$ and have a recall period from the $24 \mathrm{~h}$ (EQ-5D) to 


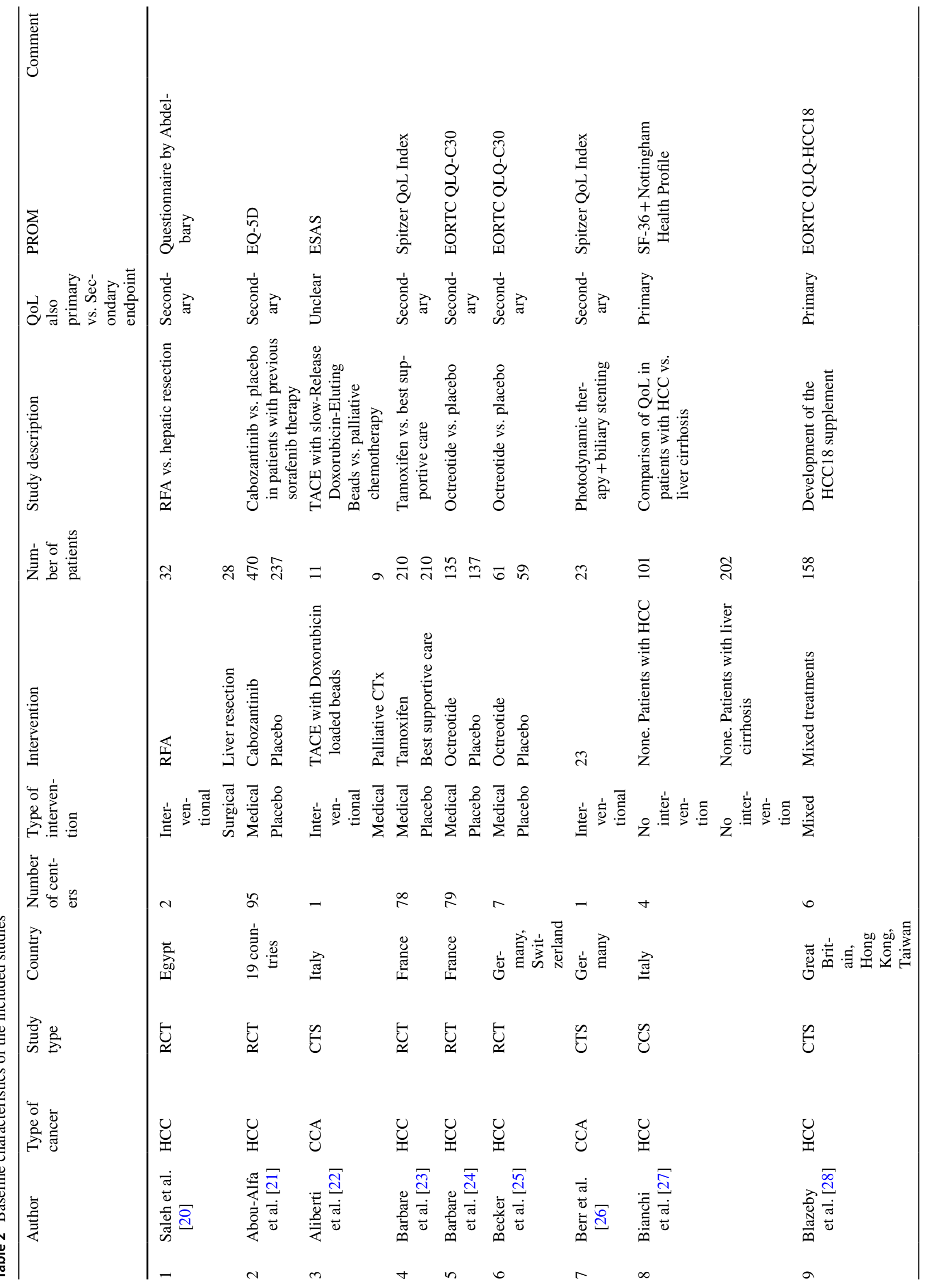




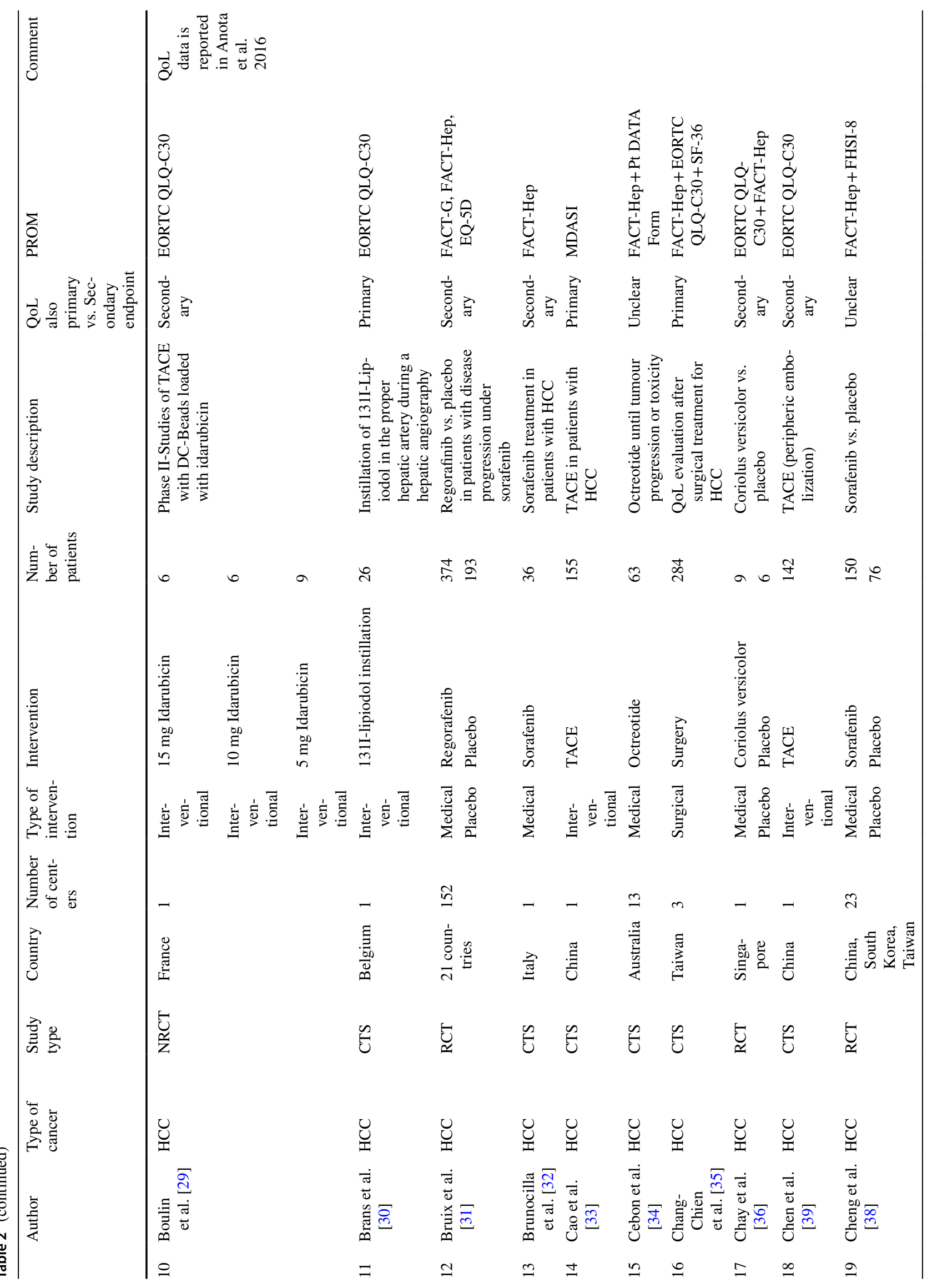




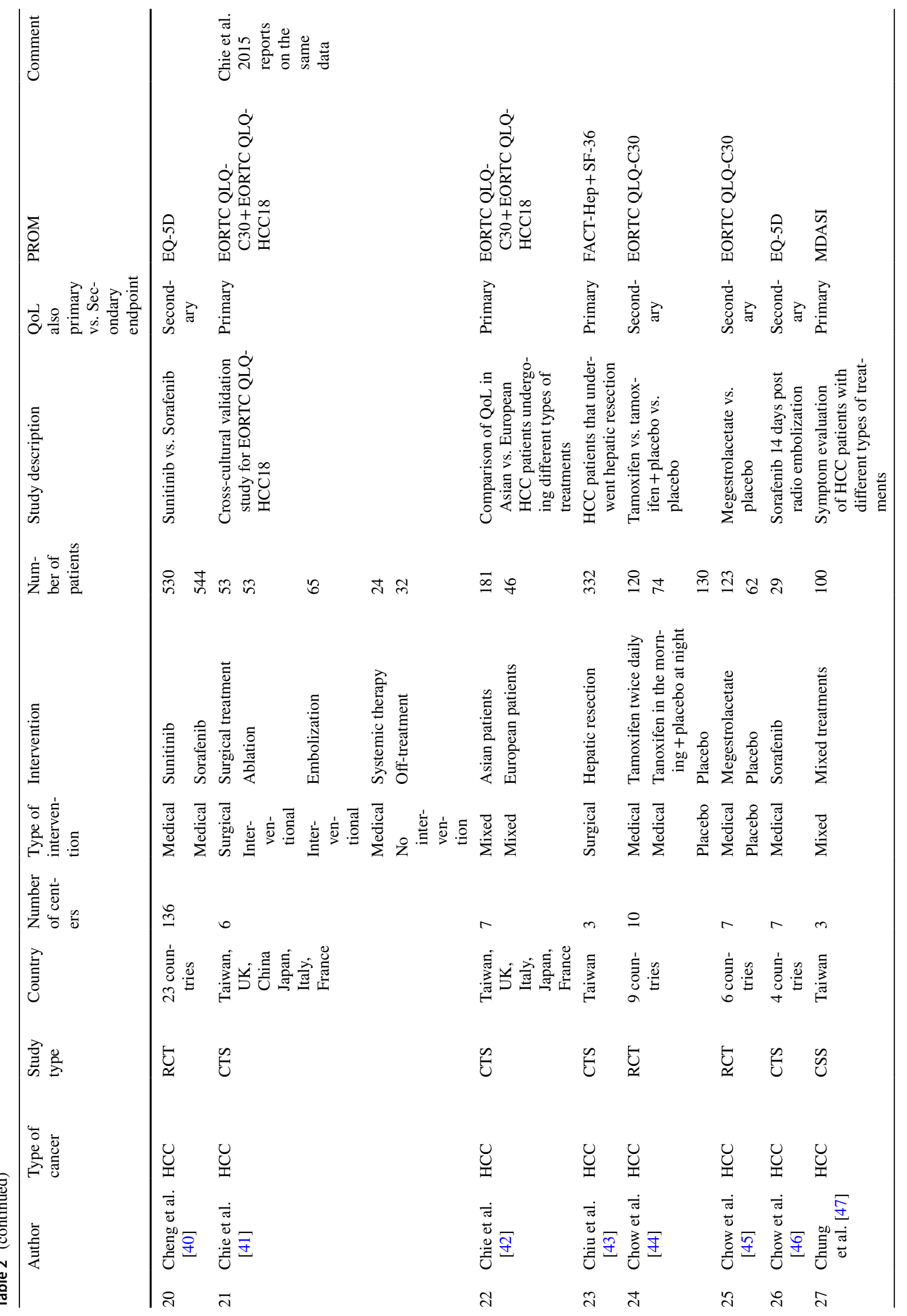




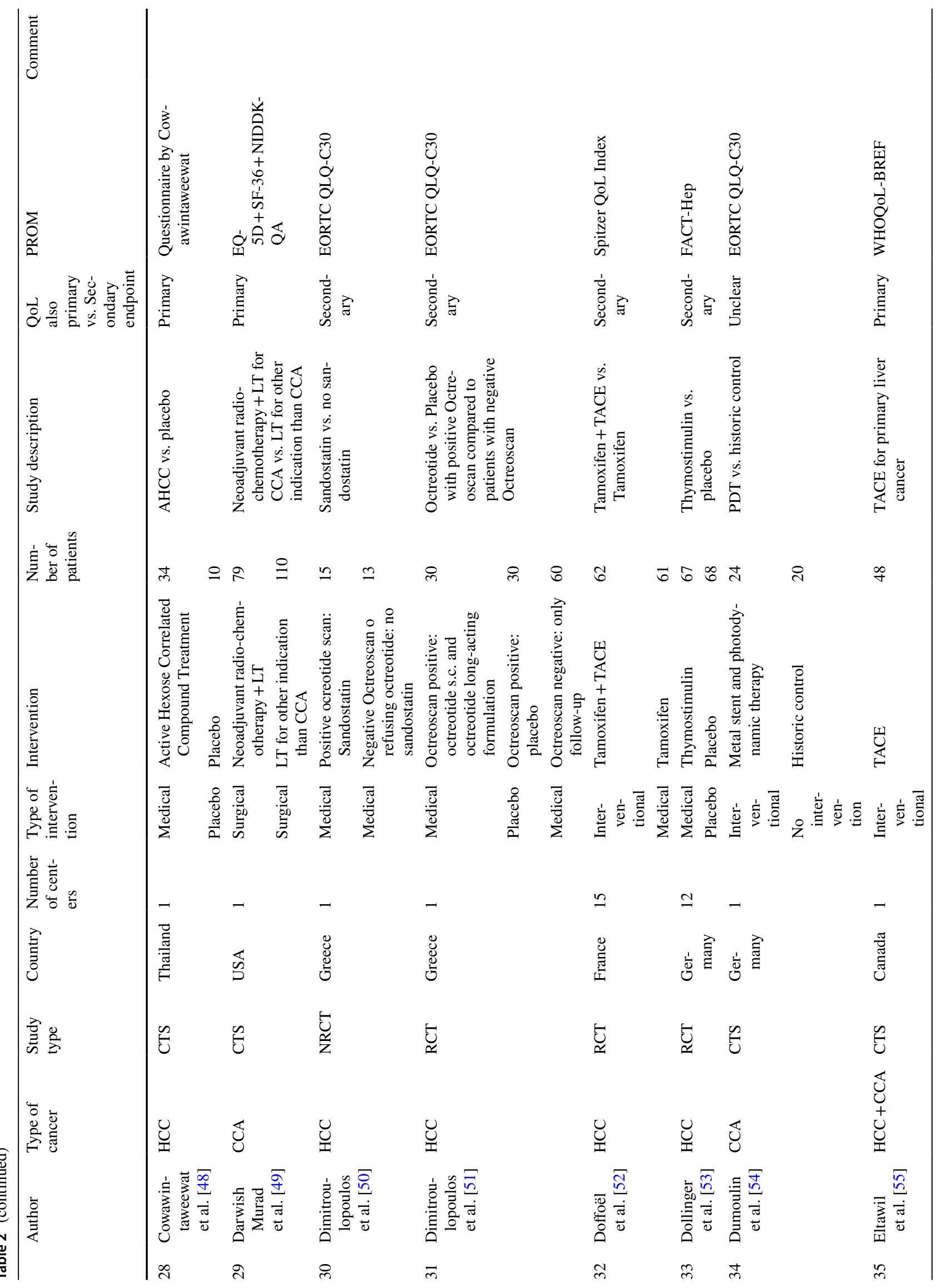




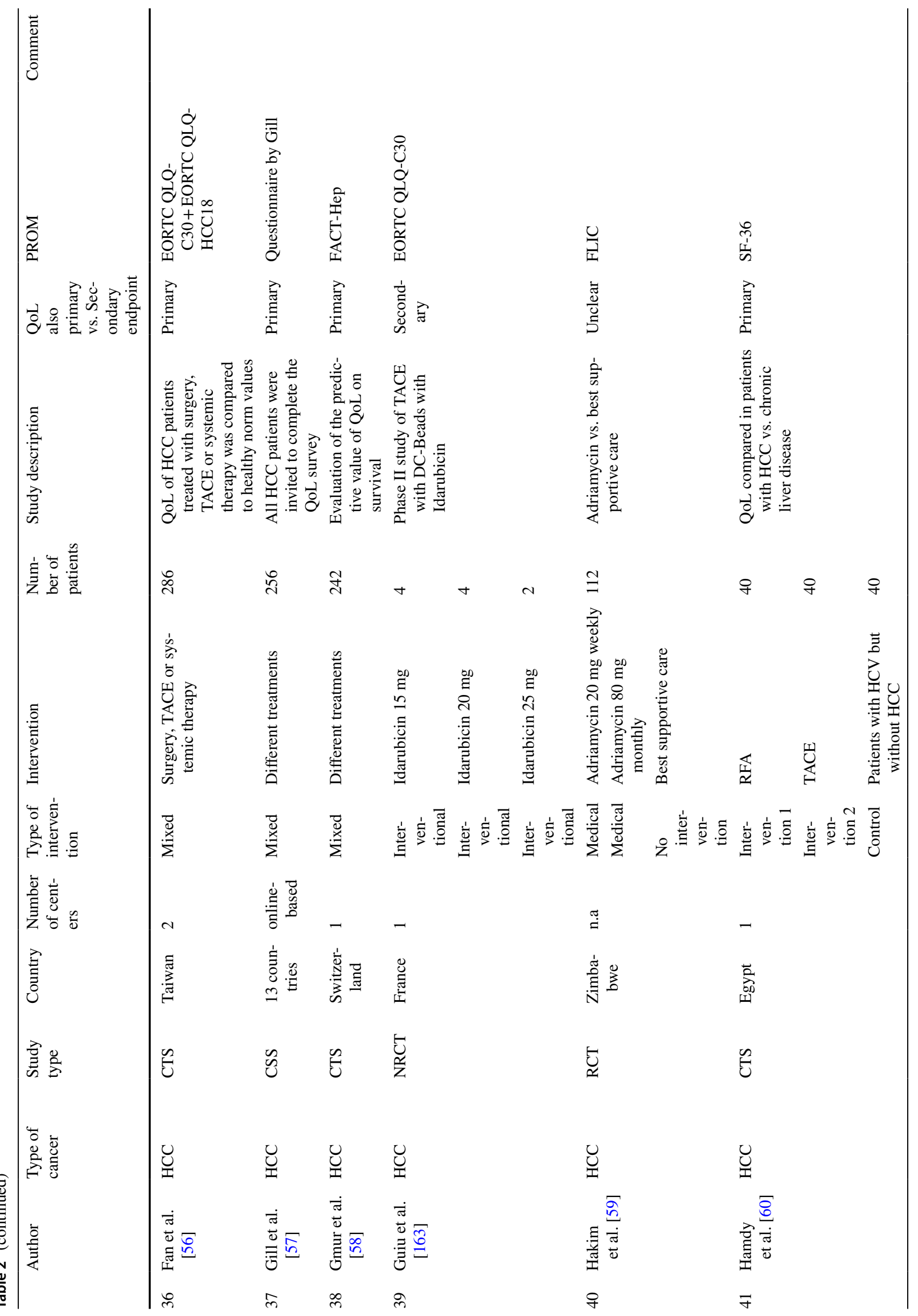




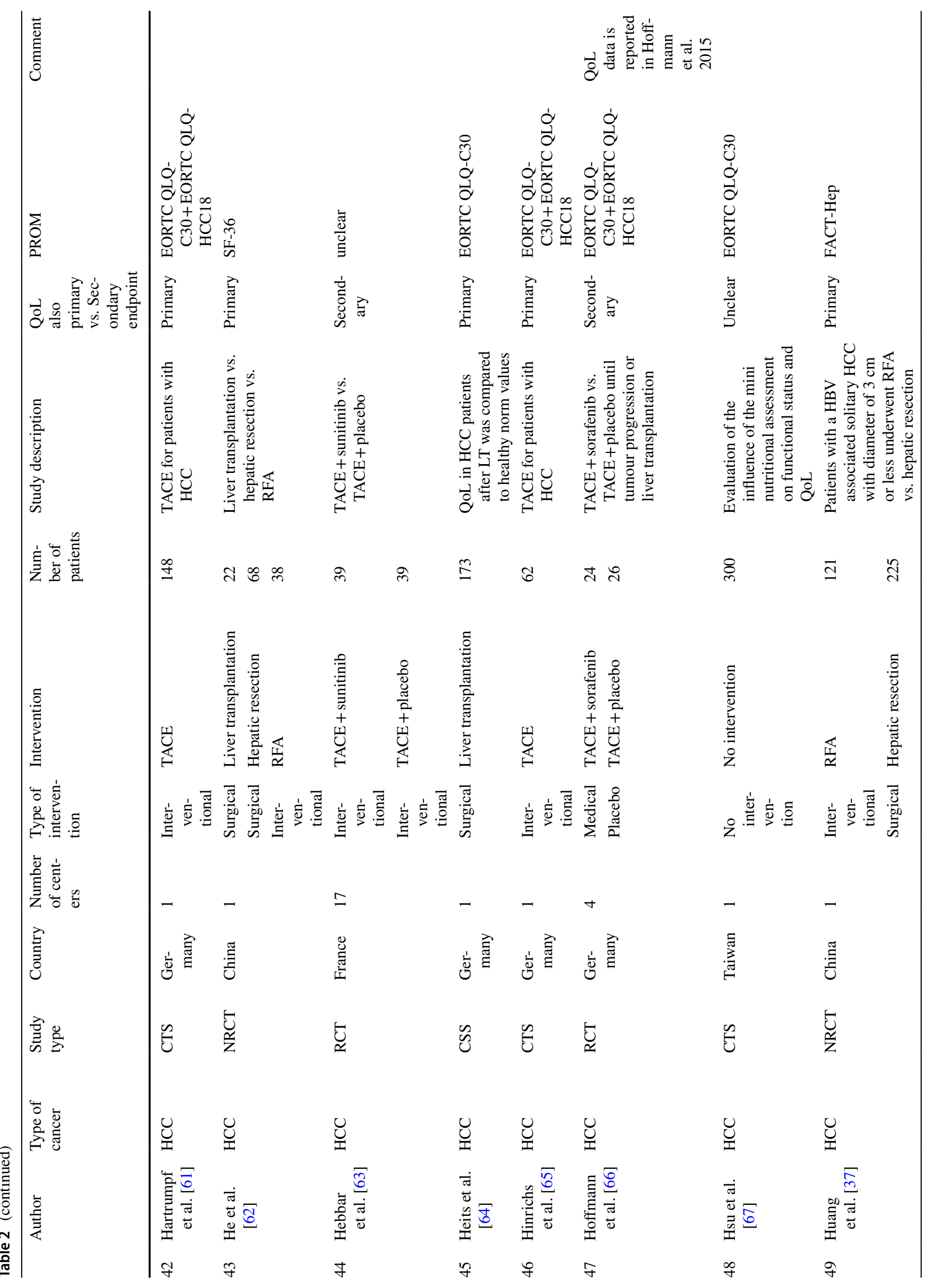









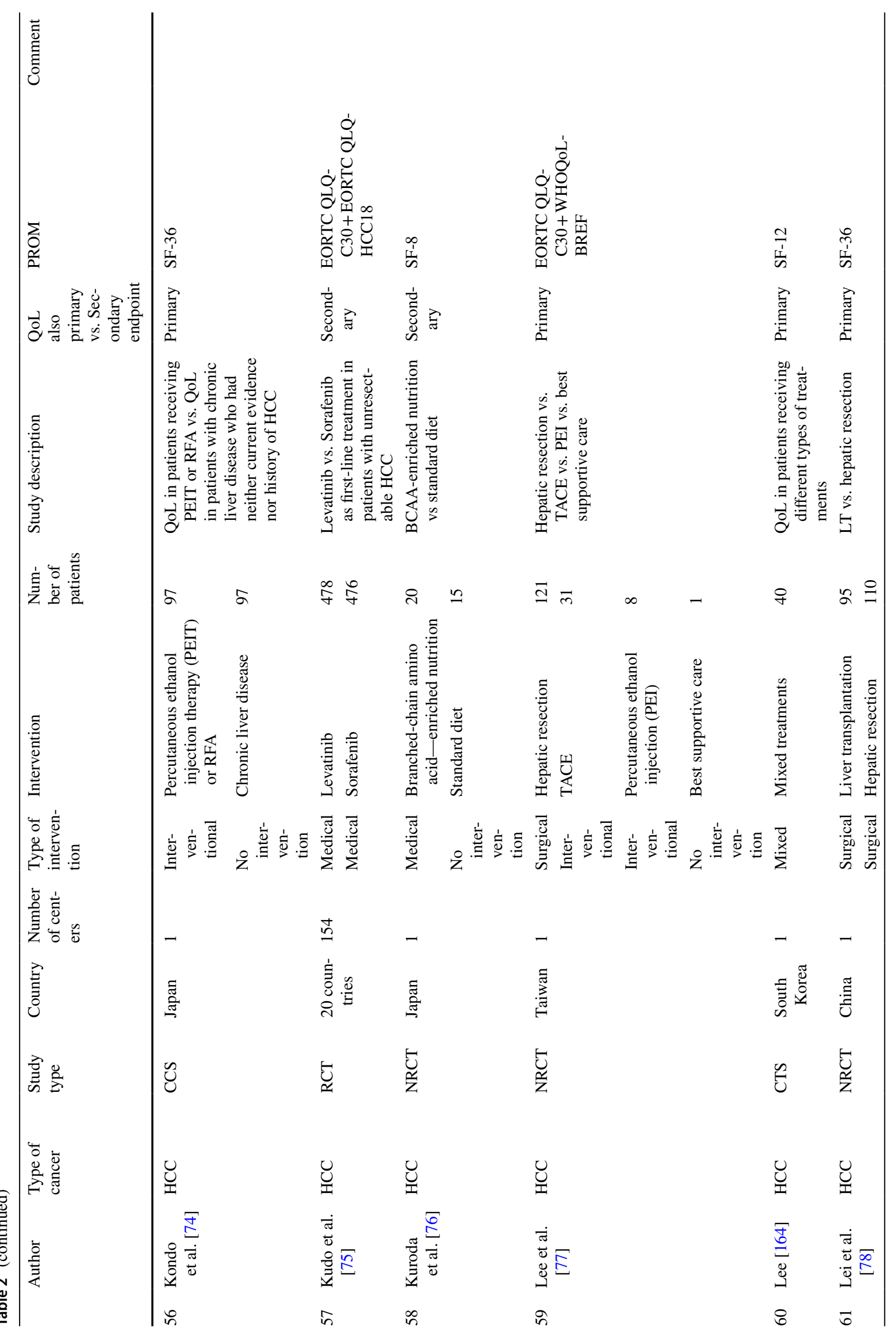




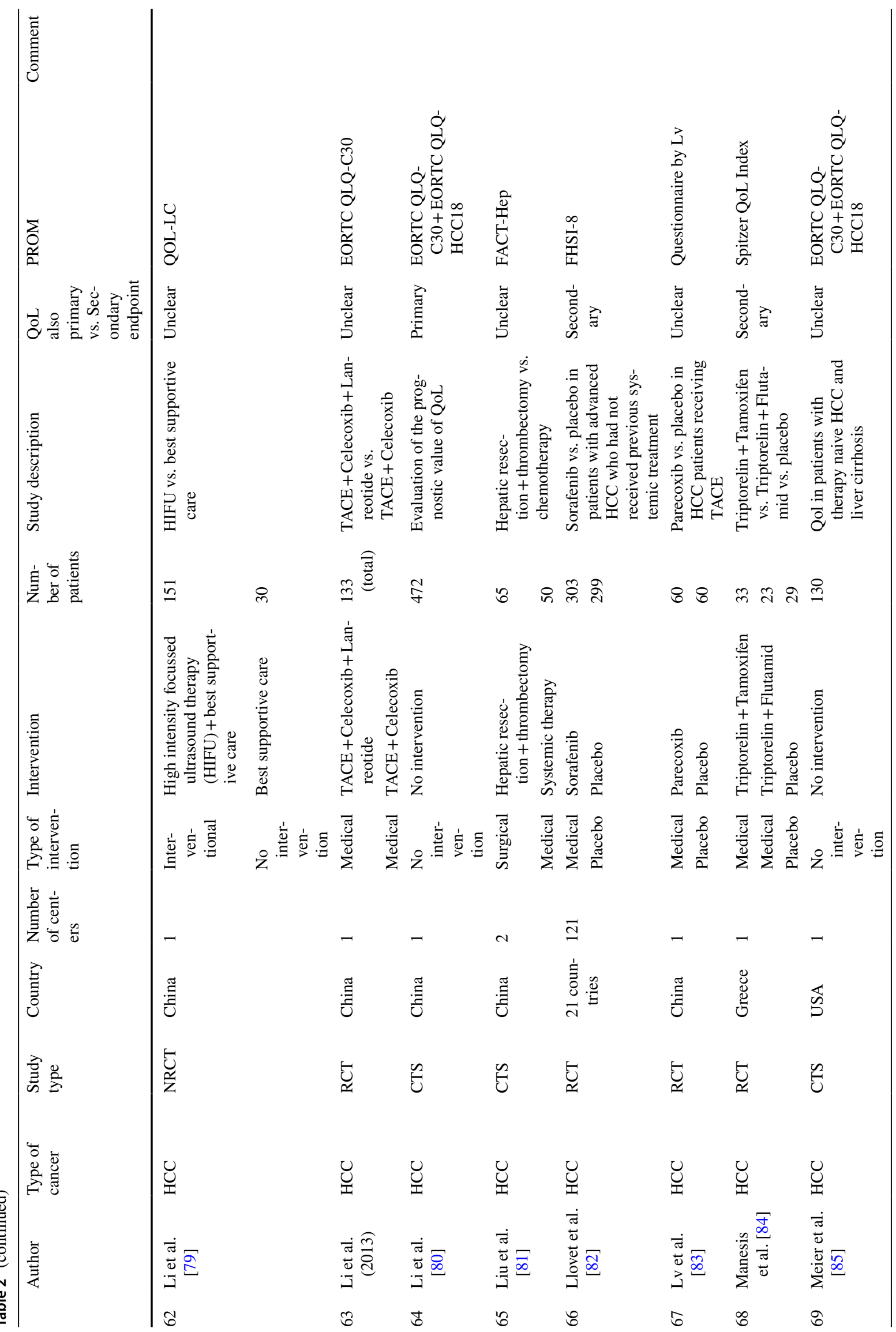









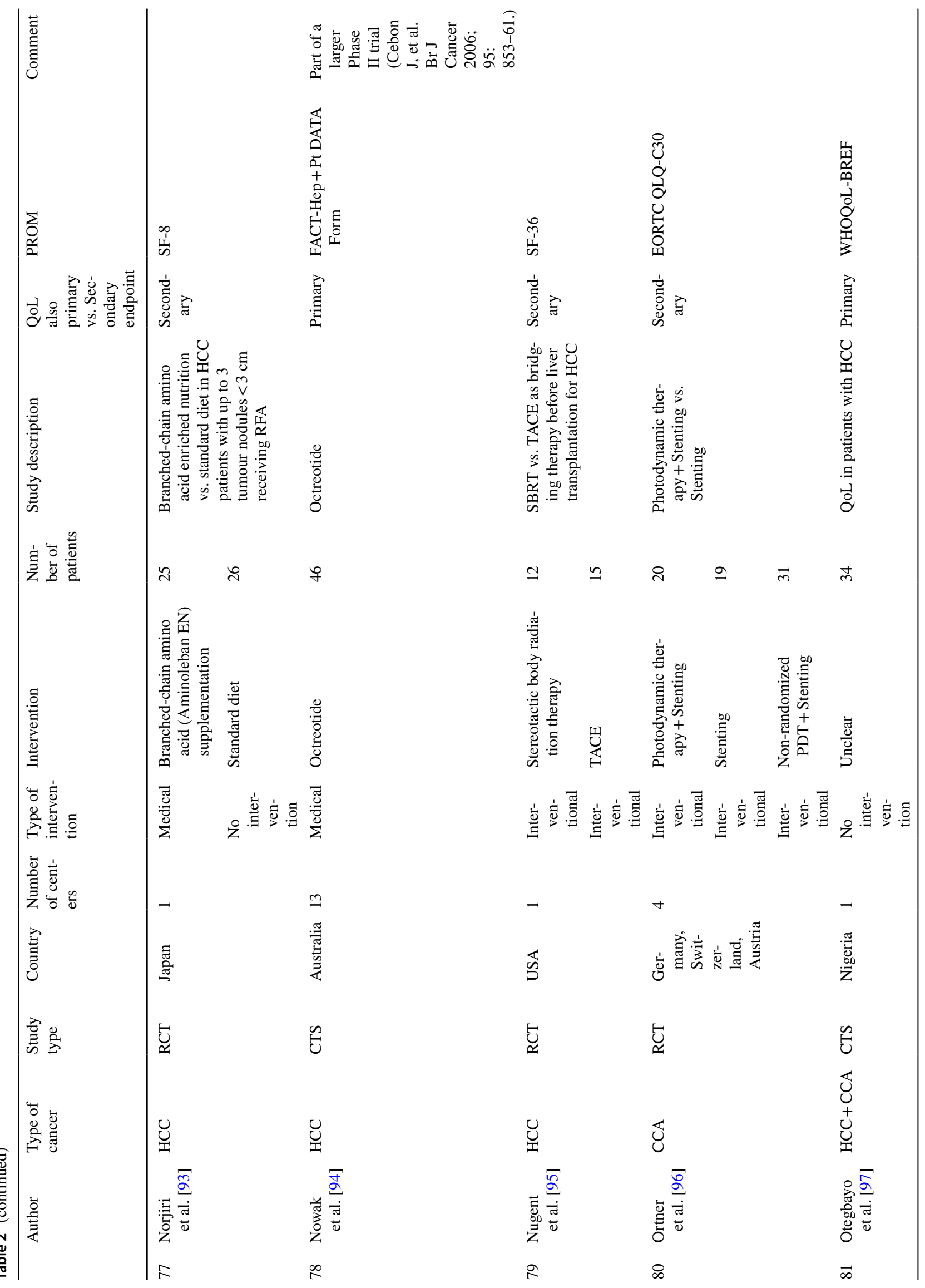




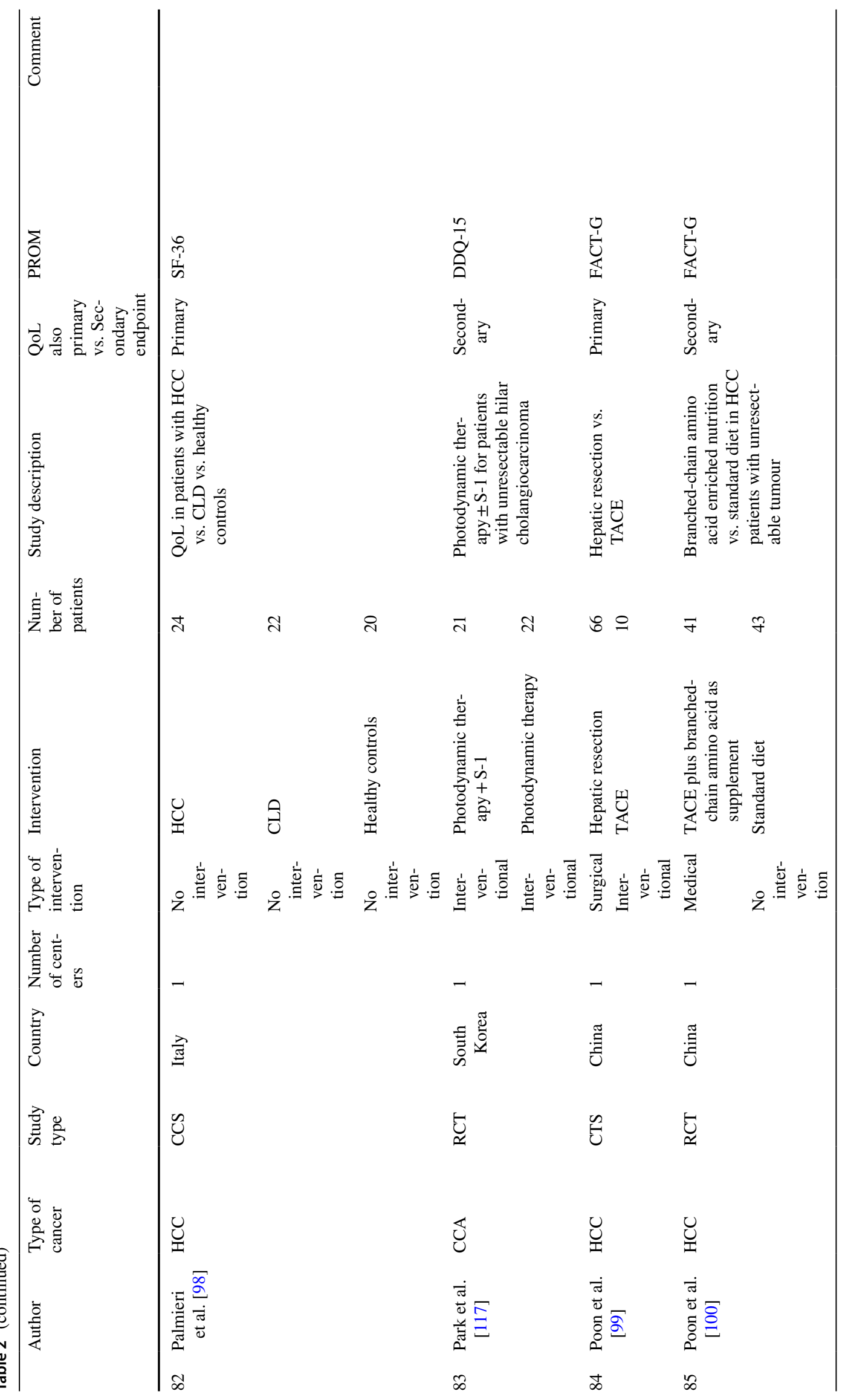




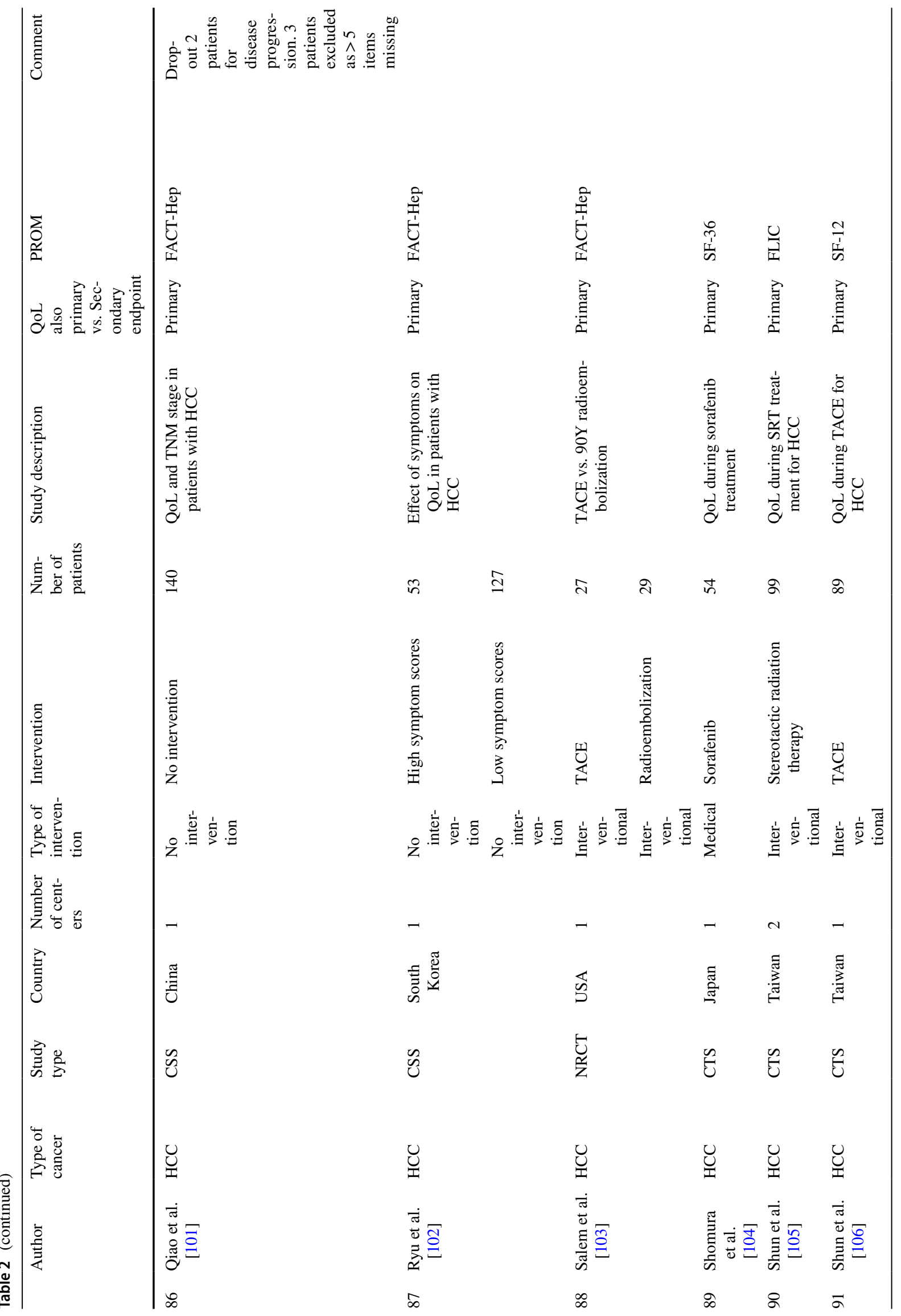


Quality of Life Research (2021) 30:2429-2466

2447

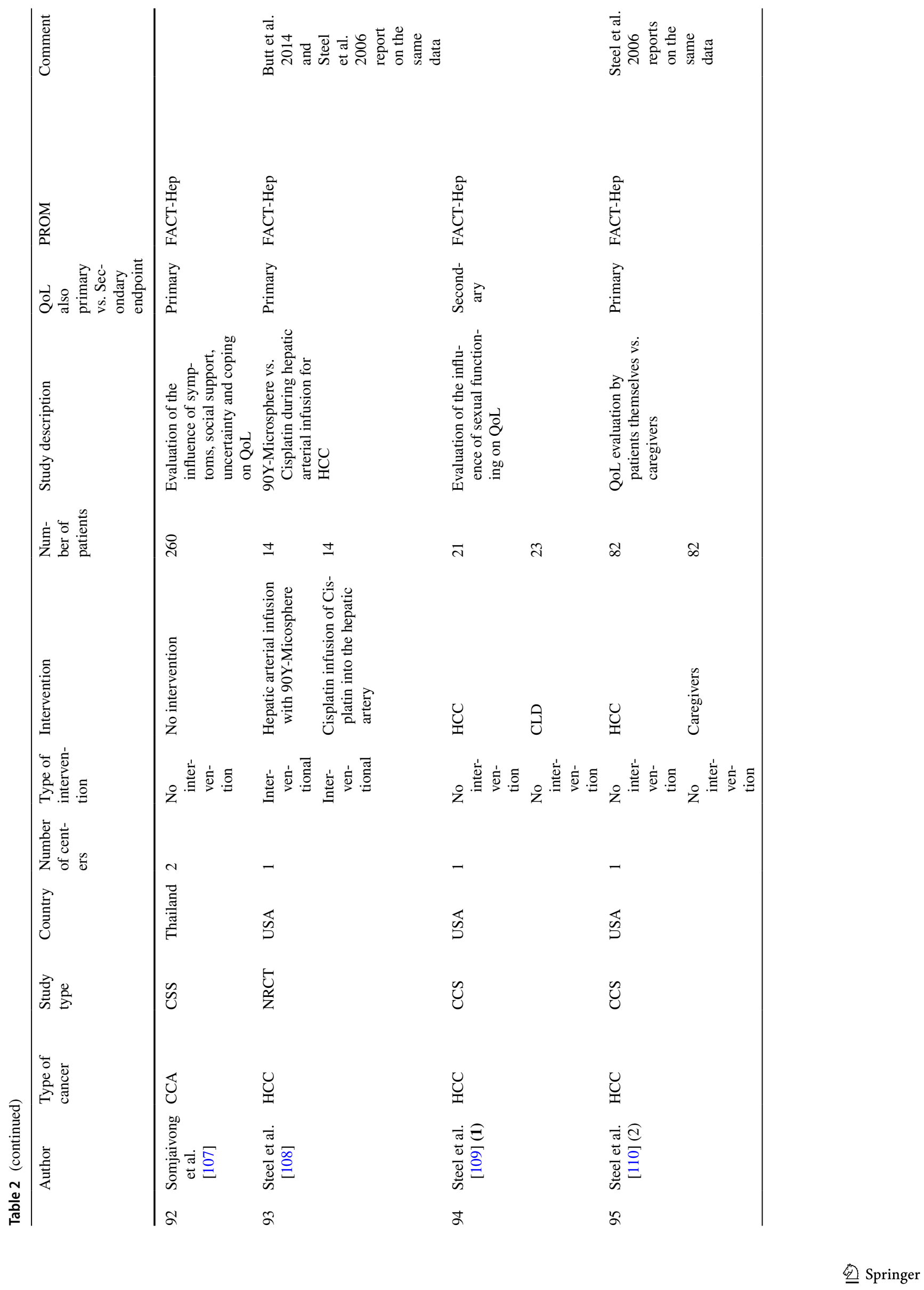









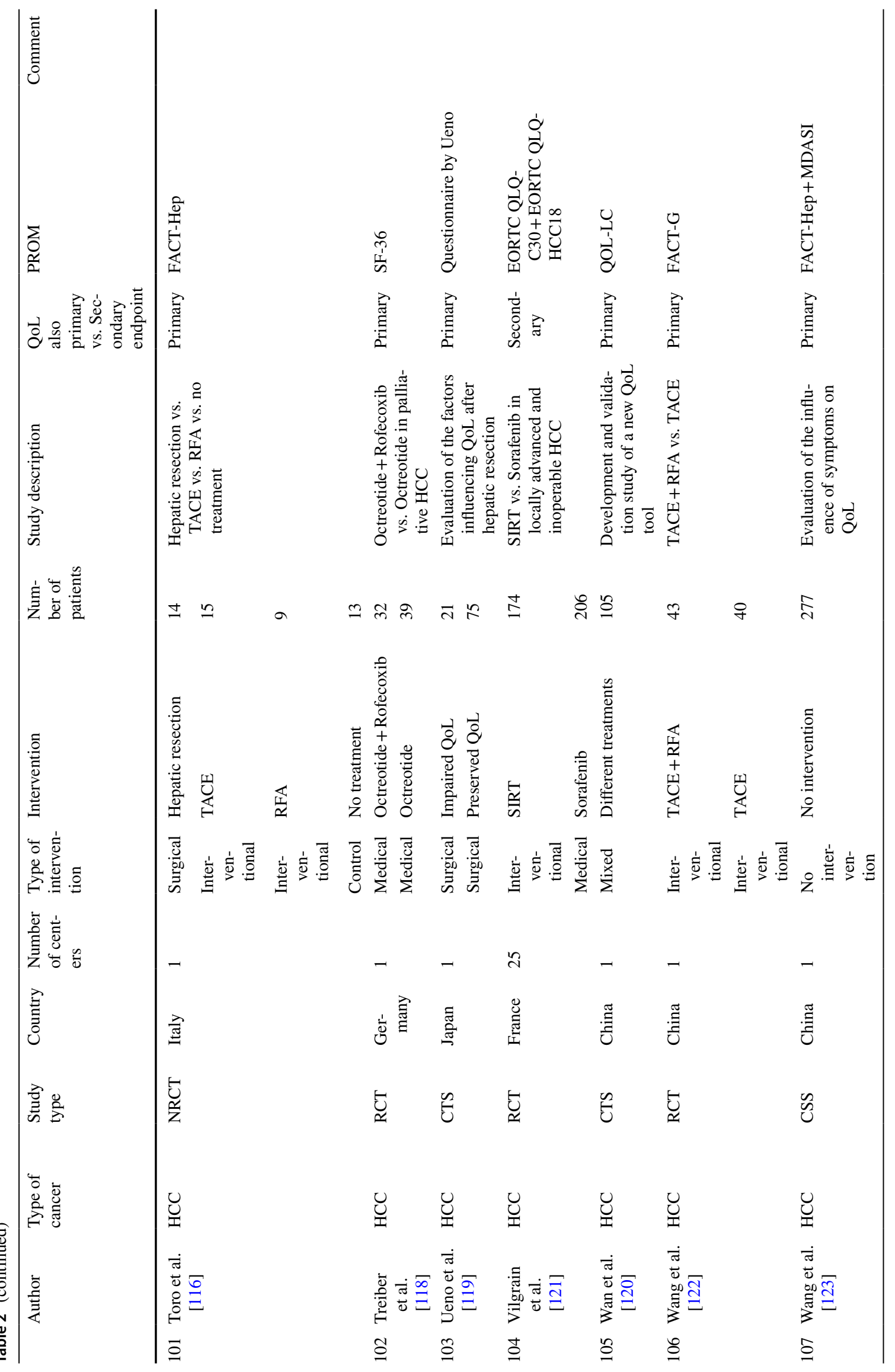




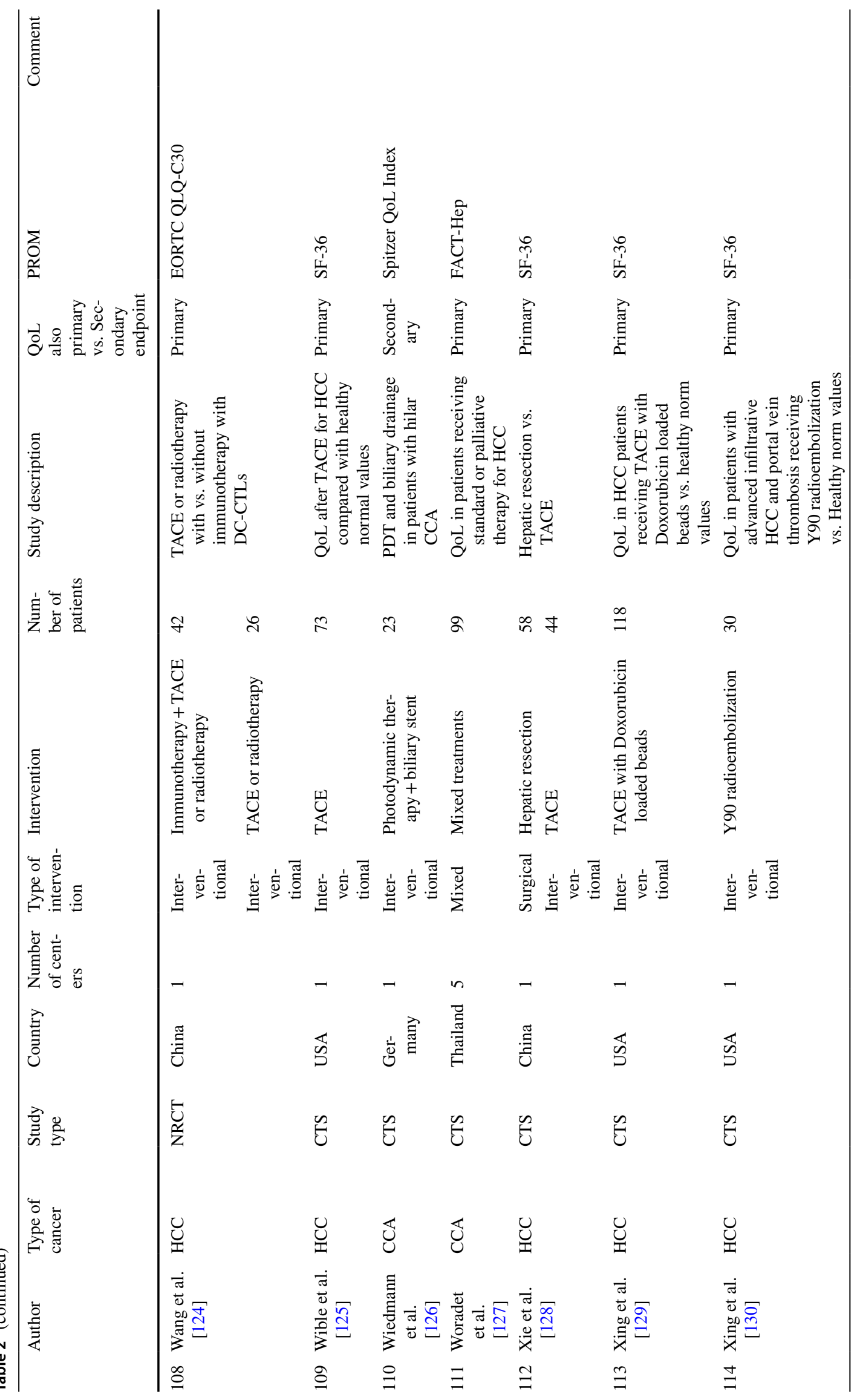




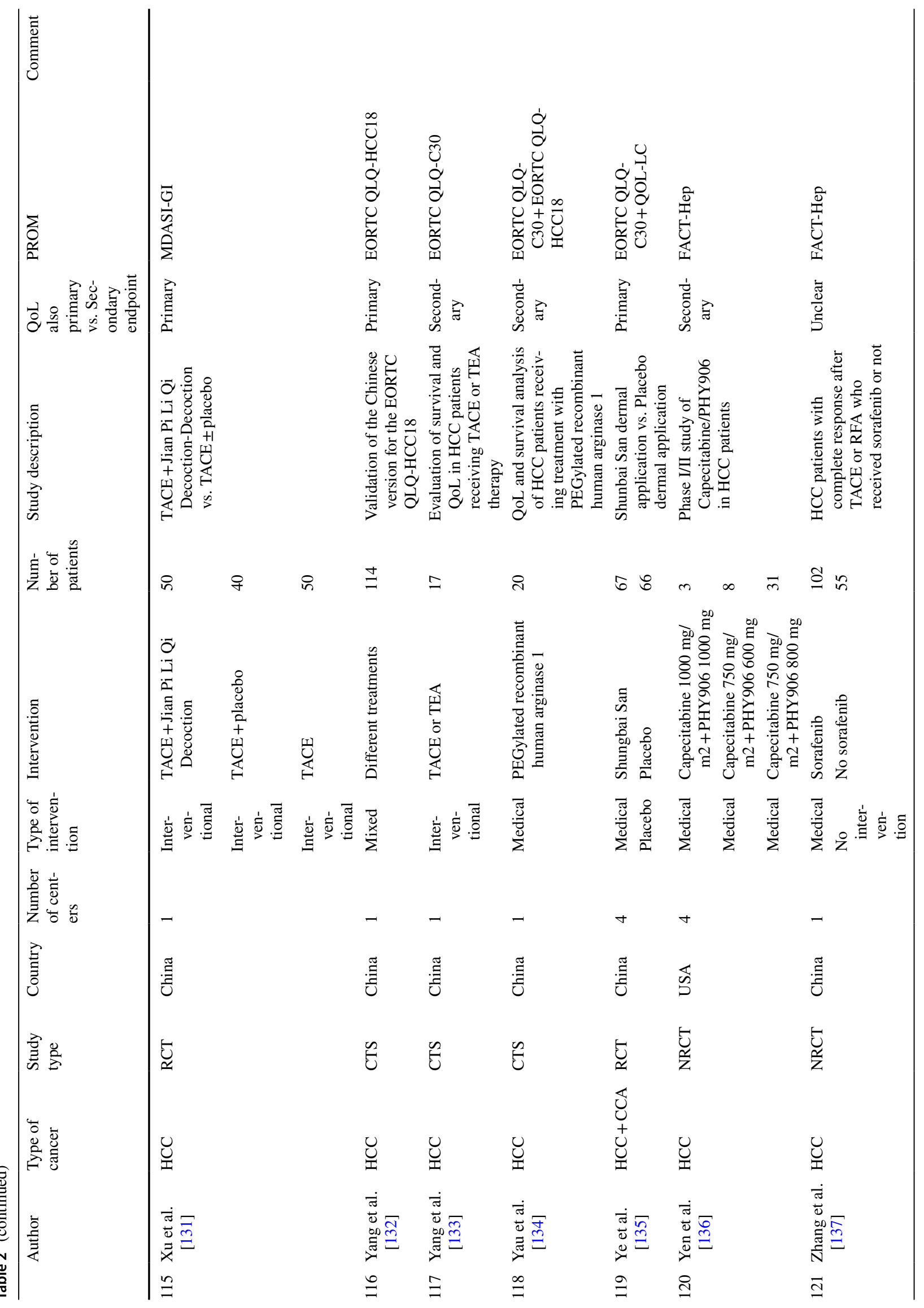




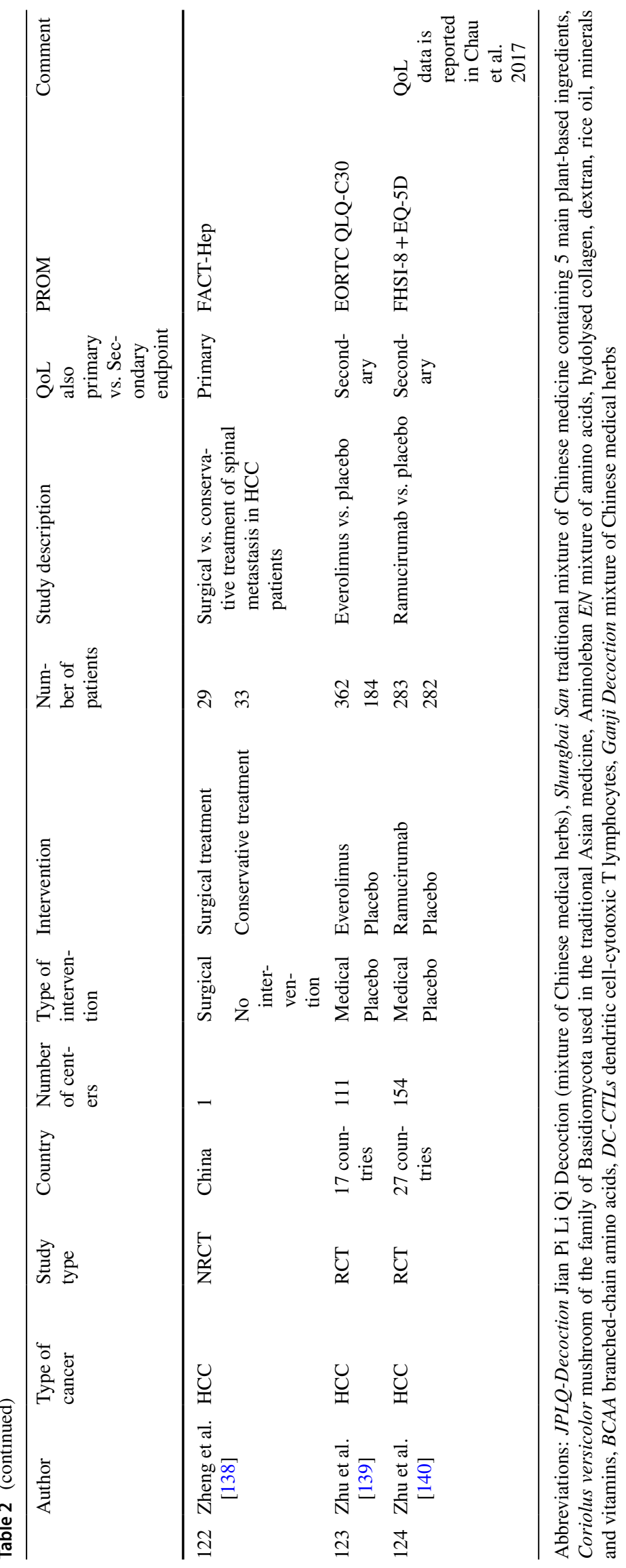


Fig. 2 Health-related quality of life instruments used in the included studies. Generic (black), cancer-specific (red), cancer-type-specific (green), utility-based (blue) and symptom index (yellow). EORTC European Organization for Research and Treatment of Cancer, EQ EuroQol, ESAS Edmonton symptom assessment scale, FACT Functional Assessment of Cancer Therapy, FLIC The Functional Living IndexCancer, Pt DATA Form Patient Disease and Treatment Assessment Form, $Q o L$ quality of life, $N I D D K-Q A$ National Institutes of Diabetes and Digestive and Kidney Diseases QoL Assessment, SF Short Form Health Survey, $V A S$ visual analogue scale, $W H O$ World Health abbreviated version of the WHOQOL-100, WHOQOL-100 WHO quality of life 100 tool Organization, WHO-BREF

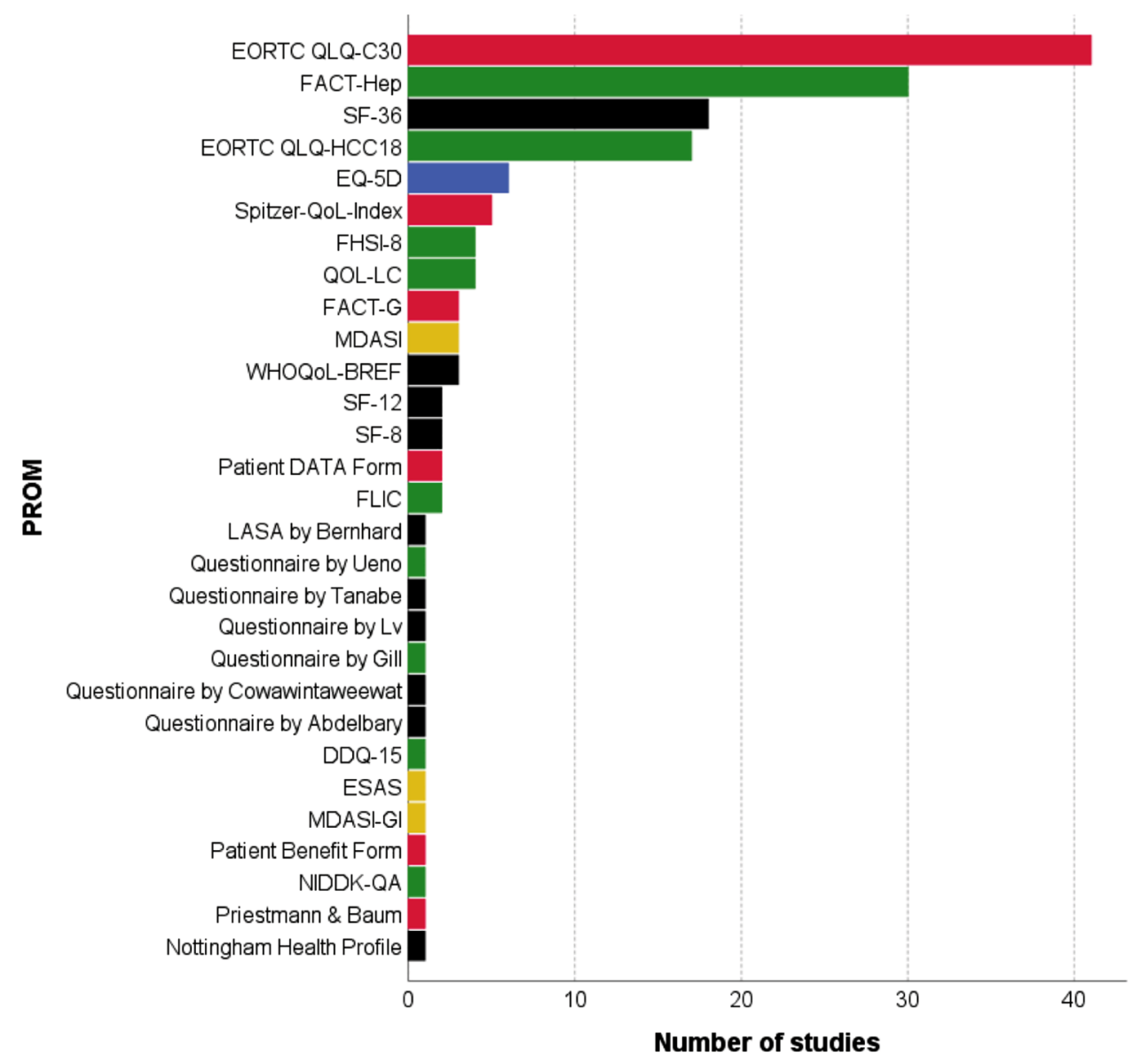

4 weeks (SF-8/12/36, Patient Benefit Form). Most of them can be completed within $10 \mathrm{~min}$.

\section{Methodological assessment of HRQoL instruments}

The methodological quality of the remaining $25 \mathrm{HRQoL}$ instruments was assessed as outlined in the methods section. Results are shown in Table 3. If no data for a given HRQoL instruments were available for HCC/CCA patients, additional Medline searches were performed to identify methodology studies that evaluated the PROM in closely related patient populations like chronic liver disease. These studies are indicated in Table 3.

The most frequently evaluated dimension in all HRQoL tools was reliability (test-retest reliability and internal consistency). With a test-retest correlation of more than 0.70 , adequate performance for 6 out of 12 PROMs (SF36, FACT-G, EORTC QLQ-HCC18, FACT-Hep, NIDDKQA and QOL-LC) was confirmed [41, 88, 120, 141-146]. For the EQ-5D, correlation coefficients ranging from 0.58 to 0.98 were observed showing that not all scales in this PROM are reliable enough [141]. Internal consistency was evaluated with the calculation of Cronbach's $\alpha$. A value greater 0.70 was considered sufficient according to
COSMIN guidelines [16]. This could be observed in 8 out of 12 HRQoL tools (NHP, SF-36, WHO-BREF, EORTC QLQC30, FACT-G, FACT-Hep, NIDDK-QA and QOL-LC) [27, $77,88,120,141,142,144-151]$. Concerning validity, rarely all three pre-defined categories (content, criterion and construct validity) were evaluated. More frequently only one or two aspects of validity were examined. Content validity was evaluated investigating the process of questionnaire creation. In case of the FACT-G, FACT-Hep and EORTC QLQ-HCC18, the process described included qualitative studies with inclusion of expert opinions, patient reports and current literature [28, 144, 152]. Merely three PROMs (FACT-Hep, FACT-Hep and NIDDK-QA) were compared to the gold standard (i.e. an already established questionnaire), thus, testing criterion validity [144-146]. In order to evaluate construct validity, group comparisons using performance status (such as the Karnofsky Performance Status) were used for the EORTC QLQ-HCC18 and FACT-Hep questionnaires as it is known that a higher performance status correlates with better HRQoL $[41,88]$. Construct validity within the SF-36 was evaluated using the correlation with hypothesized scores (conceptually related and unrelated scores) [141, 148, 149]. Kim et al. compared item scores between ambulatory patients and liver transplant recipients as well as examined 
Fig. 3 Flow chart of a included HRQoL measures and $\mathbf{b}$ number of studies from qualitative data analyses to quantitative data analyses. PROM patientreported outcome measure, $M A$ meta-analyses

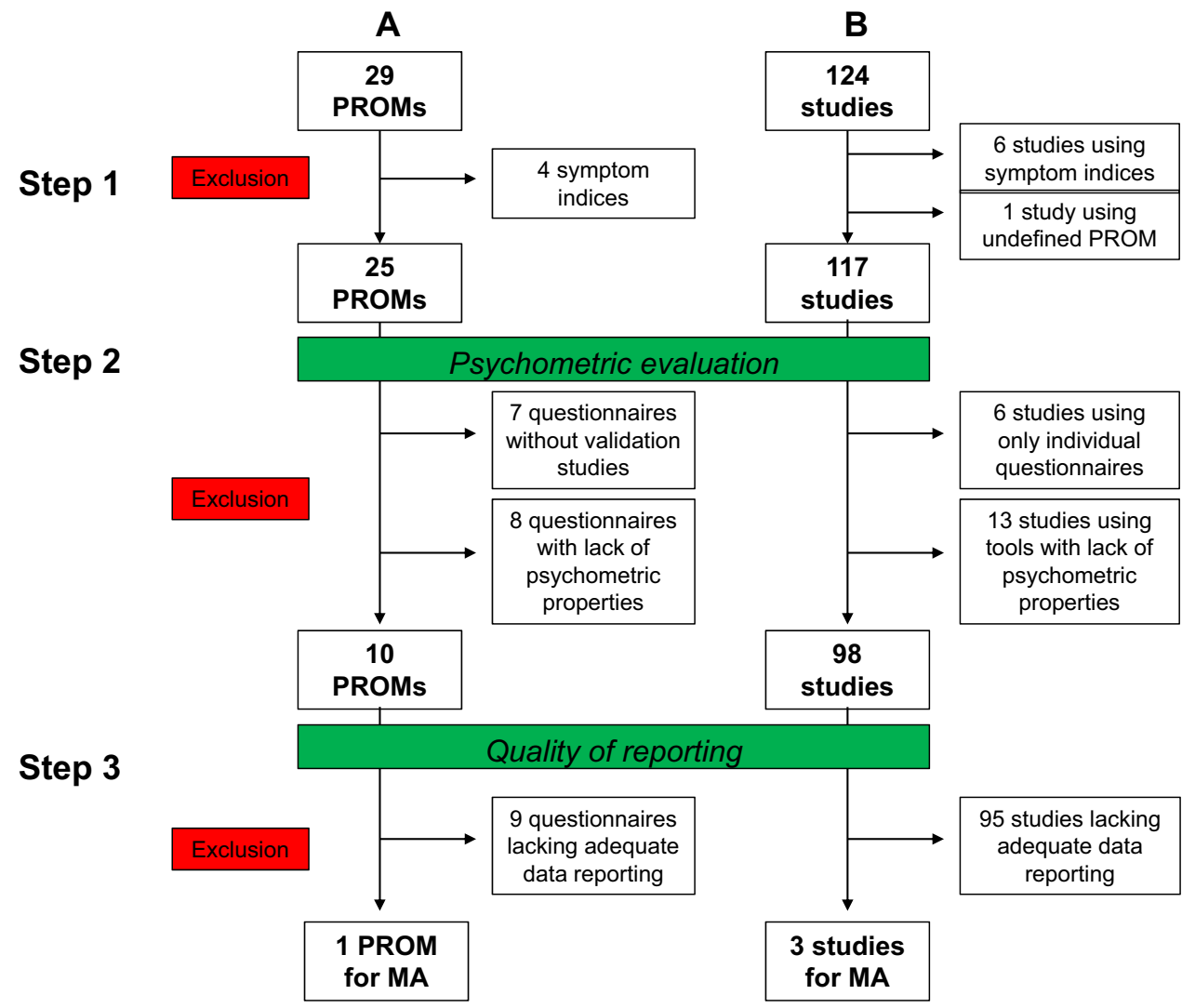

correlations between the domain scores of NIDDK-QA vs. SF-36 and Mayo risk score, respectively [146]. The Wilcoxon signed-rank test was used by Chie et al. to evaluate if the changes in score were significant before and after treatment. For example, patients undergoing surgical treatment suffered significantly more pain compared to before which reflects an adequate responsiveness of the EORTC QLQHCC18 [41]. Steel et al. evaluated the clinically meaningful changes of the FACT-Hep over time and found significant decrements in all subscales from baseline to 3-month followup [147]. The SF-36 performed poorly during the evaluation of floor and ceiling effects with patients scoring the highest or lowest possible score in distinctly more than $15 \%$ which was the set cut-off [148, 149]. Valid acceptability and feasibility were assumed when the response rate was $>80 \%$, or the time to complete the questionnaire was 10 or less minutes [24, 27, 46, 56, 85, 88, 120, 126, 141, 148, 149, 153]. The interpretability of all PROMs was considered acceptable as higher scores in QoL scales represent higher HRQoL, and higher scores within the symptom scales represent lower HRQoL.

Due to a lack of data concerning the basic psychometric evaluation or negative results, only the following $10 \mathrm{HRQoL}$ instruments were considered methodologically adequate according to the pre-specified criteria (see methods section) and were subsequently included in further analyses
(Table 3): (a) Generic HRQoL: NHP, SF-36, WHO-BREF; (b) Cancer (Condition)-specific HRQoL: EORTC QLQ-C30 and FACT-G; (c) Cancer type-specific HRQoL: EORTC QLQ-HCC18, FACT-Hep, NIDDK-QA and QOL-LC; (d) Utility (preference)-based HRQoL: EQ-5D. Only publications using one of the above-mentioned 10 HRQoL measures were included in further analyses ( $n=98$ studies) (Fig. 3 step 2).

\section{Quality of reporting of HRQoL data}

The remaining studies were evaluated for the quality of reporting of HRQoL data. Results are summarized in Supplement 3. Of the 98 included studies, 4 (4,1\%) did not specify in their methods section at what exact time points HRQoL data were measured [28, 31, 74, 79]. Many studies showed a marked discrepancy between reported HRQoL data in the results section and the frequency of HRQoL data assessment specified in the methods section. Eight studies reported only baseline HRQoL data although these trials specified in their methods section to have assessed HRQoL also during follow-up [38, 41, 42, 58, 80, 94, 98, 139]. The other 18 studies lacked reporting of HRQoL data altogether in their results section, although assessment had been announced in the methods section (supplement 3 ) $[25,28,31,44,50,53,56,66,71,74,75,80,95,97,112$, 


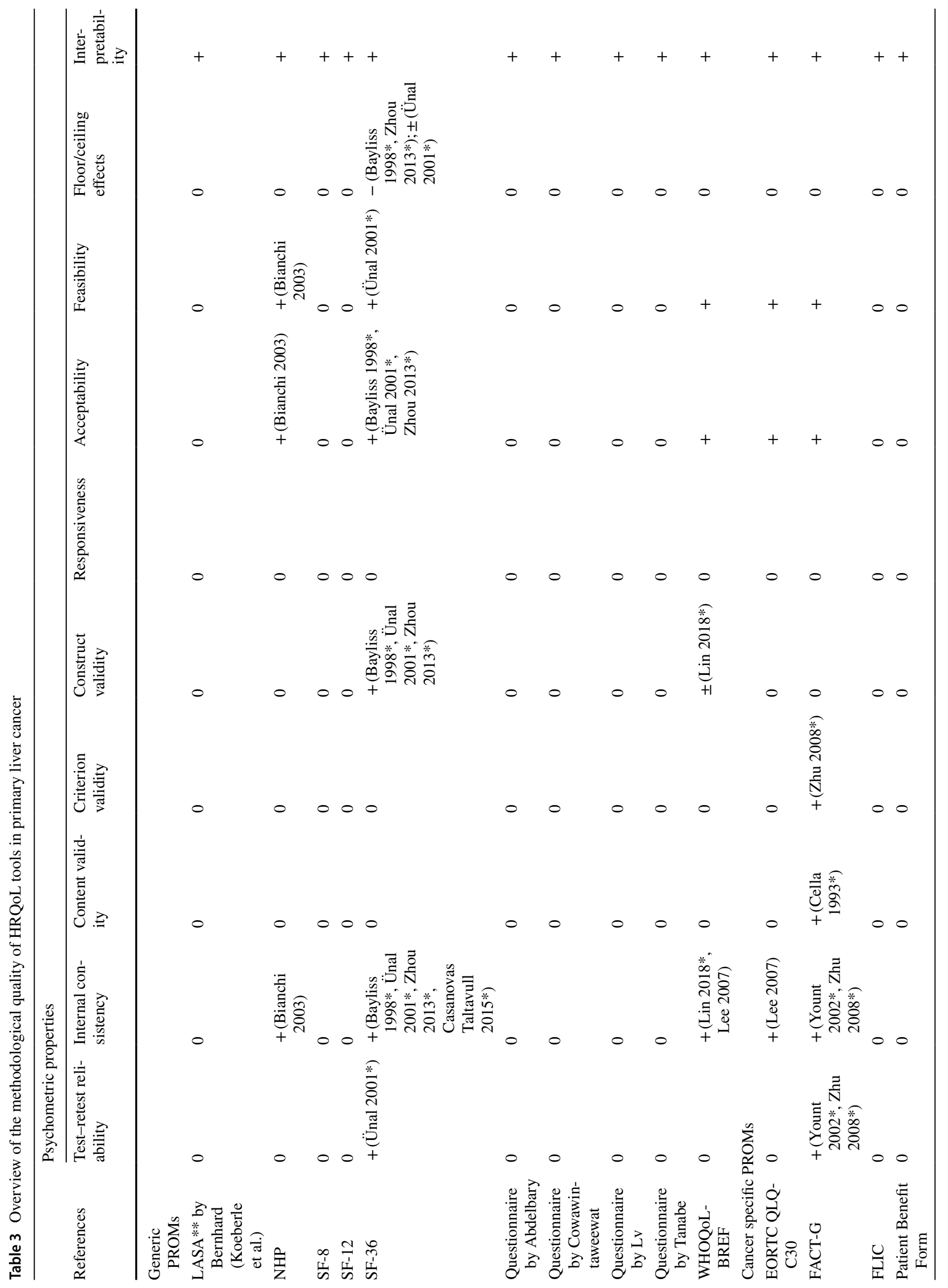




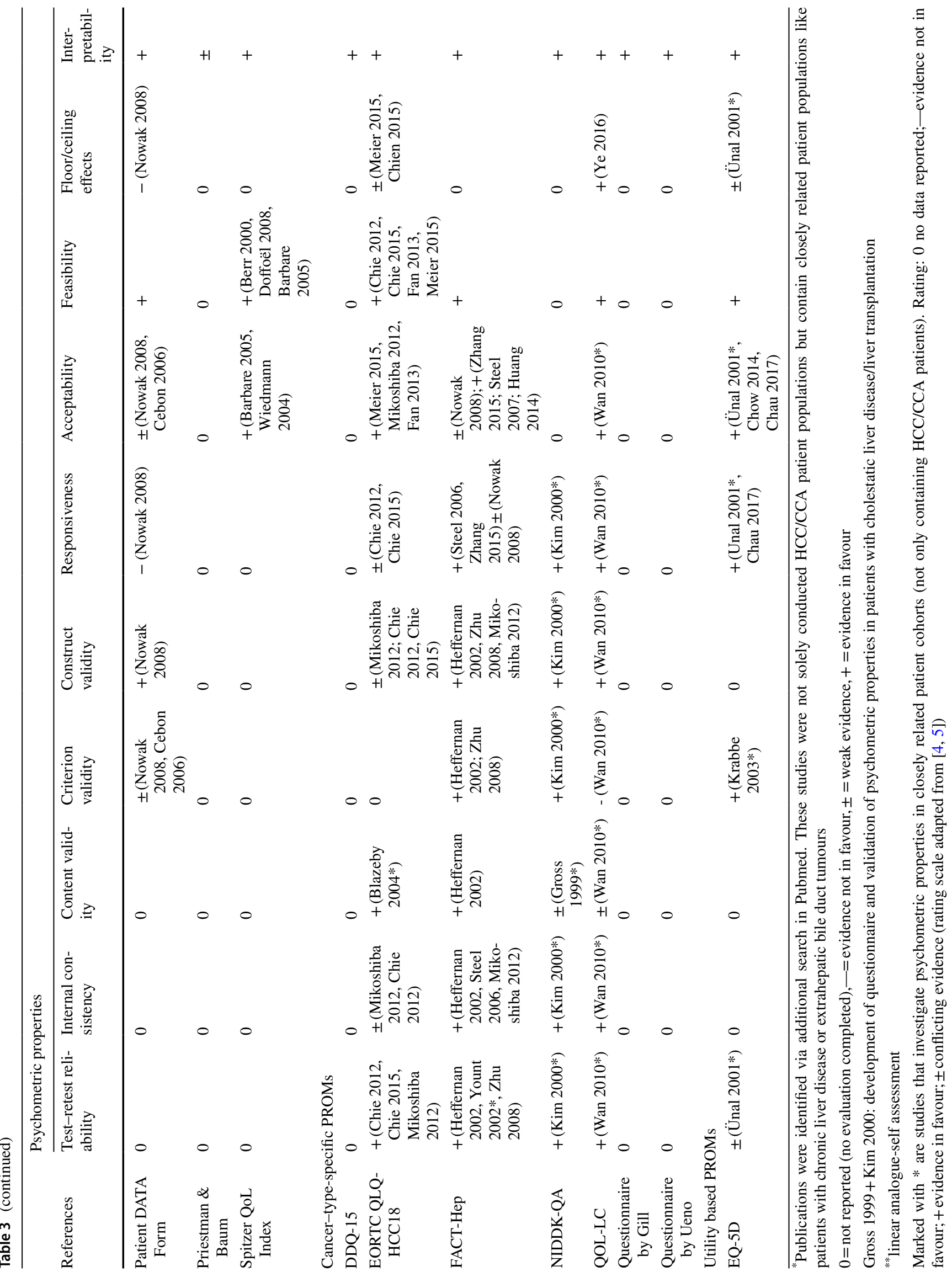


134, 136, 139]. A total of 32 studies did not report raw HRQoL data and consequently could not be used for metaanalysis $[21,25,27,29,32,34,35,38,40,44-46,49-51$, $53,56,58,66,71,75,86,95,97,112,118,128-130,134$, 136, 139]. The other 17 papers reported HRQoL data only in graphical form, which impedes meta-analysis [61, 64, 70, 72-74, 87, 90, 110, 113, 118, 121, 124, 128-130, 137]. Furthermore, although most studies reported the statistical methods, they used to analyse HRQoL, only 6 publications used a pre-specified statistical analysis plan addressing common methodological problems in HRQoL analysis [41, 43, 103, 104, 108, 125]. Finally, nine publications combined patient groups undergoing different treatment options (surgery/medical therapy/interventional treatment) for the reporting of HRQoL outcomes. In these cases, assignment of HRQoL outcomes to a specific treatment (surgery vs. medical therapy vs interventional treatment) was impossible [28, 42, 56, 58, 87, 88, 120, 127, 132]. In summary, only three studies remained for quantitative analyses (Fig. 3 step 3).

Supplement 4 illustrates the discrepancy between supposedly available and reported data for the FACT-Hep (A/B) and EORTC QLQ-C30 (C/D) HRQoL instruments.

\section{Data synthesis for HRQoL tools}

For generic HRQoL instruments like the SF-36, EQ-5D or WHO-BREF, no meta-analysis following treatment was possible, either because primary data were insufficiently reported (supplement 4) or only single articles reporting raw data were identified. Similarly, for cancer (type)-specific HRQoL tools like EORTC QLQ-C30, EORTC QLQ-HCC18 and QLQ-LC meta-analysis of HRQoL data, the following treatment was impeded by either insufficient reporting during follow-up (supplement 3), or studies compared interventions that were too heterogeneous for meta-analysis. Only for the FACT-G and FACT-Hep questionnaires, clinically comparable interventions were analysed in several studies: Six studies contained surgical study groups $[35,37,43,81$, 99, 116], two studies contained data on RFA [37, 116], and 5 studies reported extractable data in TACE patients [73, 99, 103, 116, 123]. Although FACT-G or FACT-Hep was used in several studies investigating medical treatment options for HCC, these were either single-arm studies [32, 34, 94], contained placebo control groups [31, 36, 38, 53, 137] or compared two medical treatment options [72, 136], thus, precluding a comparison to interventional/surgical treatments. Similarly, some studies used the FACT-G or FACTHep questionnaire to compare different interventional treatments [73, 103, 116, 122], again impeding meta-analysis. Consequently, only 3 studies using the FACT-G/FACT-Hep remained for meta-analysis (Fig. 3 step 3).

\section{Meta-analyses}

For the comparison of surgical resection vs. TACE, only two studies reported raw data at baseline and during followup $[99,116]$ (supplement 5A). Poon et al. split the surgical cohort into two distinct subgroups: those with a complete follow-up of two years and those with a shorter follow-up. This is likely to introduce major bias as patients completing 2-year follow-up are likely to be healthier and have less aggressive tumour diseases. We, therefore, pooled the data for the two surgical groups. Supplement 5A shows the results of this exploratory meta-analysis of the mean difference in FACT-subscores (functional, physical, social and emotional well-being) at 12-month post-intervention/surgery. One additional analysis was possible: the comparison of surgery vs. RFA as data are reported in the two studies by Huang et al. and Toro et al. [37, 116]. Supplement 5B shows the results of the exploratory meta-analysis for the 12-month post-interventional/postoperative follow-up, again comparing mean differences in FACT-subscores.

\section{Discussion}

HRQoLs represent an important domain of clinical outcomes in oncology. While definitions, implementation, evaluation and analyses of survival and toxicity/complication endpoints have been well standardized over the last decades, PROs are still under-evaluated and reported in most clinical settings. Multiple studies have aimed to define suitable HRQoL tools for different clinical settings, e.g. [4, 5], including cancer patients [6-8]. However, no concise evaluation has been performed for patients with primary liver cancers (HCC or CCA).

Although 124 studies were included in this systematic review, we were able to complete only the first two objectives of our study, namely to identify and evaluated HRQoL measures in HCC/CCA patients. However, meta-analysis of study results comparing the outcome of surgical, interventional or medical treatments for HCC/CCA patients in regard to HRQoL was barely possible due to the use of different HRQoL instruments, lack of data or insufficient reporting.

We identified 29 different HRQoL instruments, which indicate vast heterogeneity and lack of consensus in this field. Similar results have been reported before in other diseases [6-8]. Furthermore, many of the identified tools lacked basic HRQoL characteristics like multidimensionality $[154,155]$. Hence many authors seemed to be unaware of the difference between mere symptom measures and HRQoL instruments. In addition, validation of HRQoL is poor for most instruments in HCC/CCA patients (Table 2). As expected, the best psychometric data were available for cancer-type-specific HRQoL instruments, like EORTC 
QLQ-HCC18 or the FACT-Hep. Interestingly, even for common generic and disease-specific HRQoL tools, like the Spitzer quality of life index and the EORTC QLQ-C30, data in HCC/CCA patients are sparse. Hence, evaluation of these common tools in this patient cohort seems necessary in future studies. In addition, even for HRQoL measures developed especially for liver cancer patients, psychometric properties were less stringent as might have been thought. The EORTC QLQ-HCC18 shows mixed psychometric results [41, 88]. FACT-Hep, on the other hand, although showing good psychometric properties, has been validated only in mixed patient populations including patients with liver metastases and pancreatic cancer in addition to HCC/CCA patients [144, 147]. Similarly, the preference-based HRQoL EQ-5D has been extensively evaluated in chronic liver disease, but little psychometric data are available in HCC/CCA patients. Future studies should address these shortcomings.

Nevertheless, our analysis revealed suitable HRQoL instruments with sound psychometric properties that should be used in all future HRQoL studies. These are SF-36 [156] for generic HRQoL measurement. The SF-36 is a generic HRQoL instrument consisting of 36 items divided into eight scales (Physical Functioning, Emotional Role Functioning, Physical Role Functioning Bodily Pain, General Health, Vitality, Social Functioning, Mental Health, Health Transition) [156]. The number of response choices per item ranges from two to six. The scores for each scale range from 0 to 100. A higher score indicates a better QOL. The time frame of the SF-36 is 'last week' [141].

For cancer-specific HRQoL measurement in HCC/CCA patients, the EORTC QLQ-C30 [157] and the FACT-G can be recommended. Both have limited, but acceptable psychometric properties in HCC/CCA patients and have been used extensively in this patient cohort. The 30-item QLQ-C30 measures five functional scales (physical, role, emotional, cognitive and social functioning), global health status, financial difficulties and eight symptom scales (fatigue, nausea and vomiting, pain, dyspnoea, insomnia, appetite loss, constipation and diarrhoea). The scores vary from 0 (worst) to 100 (best) for the global health status and functional scales, and from 0 (best) to 100 (worst) for symptomatic scales [157]. The FACT-G consists of 27 items for the assessment of four domains of QOL: (1) Physical Well-Being and (2) Socio-Family Well-Being contain seven items each; (3) Emotional Well-Being contains six items and (4) Functional Well-Being contains seven items. The time frame of the FACT-G is 'last week'. Each item is scored on a 5-point ordinal scale, where 0 indicates not at all and 4 , very much [152].

Cancer-type-specific HRQoL should be measured via the EORTC QLQ-HCC18 or FACT-Hep. The EORTC QLQ-HCC18 is an 18-item HCC-specific supplemental module developed to augment QLQ-C30 and to enhance the sensitivity and specificity of HCC-related QOL issues. It contains six multi-item scales addressing fatigue, body image, jaundice, nutrition, pain and fever, as well as two single items addressing sexual life and abdominal swelling. The scales and items are linearly transformed to a 0 to 100 score, where 100 represents the worst status [28, 88]. The FACT-Hep is a 45-item self-reported instrument that consists of the 27-item FACT-G (see above), and the 18-item hepatobiliary cancer subscale, which assesses specific symptoms of hepatobiliary cancer and side effects of treatment. The FACT-G and hepatobiliary cancer subscale scores are summed to obtain the FACT-Hep total score [37, 144]. The QoL-LC questionnaire shows good psychometric properties but has been developed and tested exclusively in Chinese patients, thus, limiting its generalizability. Similarly, NIDDK-QA as a cancer-type-specific $H R Q o L$ tool has been used in only one study and, thus, cannot be recommended currently.

For utility-based HRQoL measurement, the EQ-5D [158] has been identified as the instrument of choice. It fulfils basic psychometric requirements, and a sound database is available in HCC/CCA patients. The EQ-5D consists of five items (mobility, self-care, usual activities, pain/discomfort and anxiety/depression). Each item has three response categories: no problems, some problems and extreme problems. The sixth item is a global health evaluation scale, ranging from 0 (the worst imaginable health state) to 100 (the best imaginable health state). The time frame of the EQ-5D instrument is the present moment.

The quality reporting of the HRQoL results was insufficient overall. Few trials reported common methodological problems of HRQoL data like multiple testing, missing data or a priori hypothesis. Raw data were rarely reported and summarize measures (mean, median etc.) as well as follow-up regimes varied widely between studies. In addition, the methodological quality of the studies was generally poor. Thus, despite a total of 124 studies available, evidence regarding HRQoL in HCC/CCA patients is limited.

It is astonishing that reporting of HRQoL data does not seem to have improved over the last decades despite the publication of multiple guidelines and recommendations concerning HRQoL reporting. Few of the included studies fulfiled basic reporting standards for HRQoL like the ones proposed by Basch et al. [159], Staquet et al. [160], the International Society for QoL research (ISOQOL) [161] or the CONSORT-Patient-reported outcome extension [162].

These shortcomings in the methodological quality and reporting were the main reasons for the insufficient metaanalyses in our study. Studies had to be excluded at various points along the way (Fig. 3). The planned comparison of treatment options (surgery vs. medical treatment vs. interventional treatment) with regard to HRQoL can, therefore, be regarded exploratory at best. Future, high-quality 
HRQoL trials, adhering to basic reporting standards, are urgently needed to address these shortcomings.

One of the main strengths of the current study is the use of a comprehensive search strategy to identify all relevant publications. Furthermore, to our knowledge, this is the first study that assesses the methodological quality of HRQoL tools in HCC/CCA patients according to internationally accepted standards time $[3,15,16]$ thereby identifying suitable HRQoL instruments for the use in future studies. In addition, this study can be used as an easy reference standard to identify available studies and raw data for the design and sample size calculation in future $\mathrm{HCC} /$ CCA trials. The transparent analysis process in this study can be regarded as a further strength.

The main limitation of our analysis is the heterogeneity of included studies, patients and trial designs. The variations in the application, analyses and reporting of HRQoL between studies made data synthesis difficult. The metaanalyses should regarded exploratory at best.

In summary, clear recommendations for generic, cancer-specific, cancer-type-specific and preference-based HRQoL instruments in HCC/CCA patients can be given. Meta-analysis of data comparing different treatment options in HCC/CC patients was severely limited due to methodological weaknesses of the included studies and shortcomings in reporting. Future trials should address these aspects and adhere to HRQoL reporting standards.

Supplementary Information The online version contains supplementary material available at https://doi.org/10.1007/s11136-021-02810-8.

Author contributions KW, ALM, MKD and CE are responsible for conception and design of the study. KW, PH and ALM performed the acquisition and analysis of the data, and drafted the manuscript. $\mathrm{KW}, \mathrm{PH}, \mathrm{PP}, \mathrm{CE}, \mathrm{MKD}$ and ALM offered substantial contributions to interpretation of the data and critically revised the manuscript. All authors gave their final approval of this version of the manuscript and are accountable for all aspects of the work

Funding Open Access funding enabled and organized by Projekt DEAL. No funding was used to create this review.

Data availability Not applicable.

Code availability Not applicable.

\section{Declarations}

Conflict of interest All authors declare no conflict of interest.

Ethical approval Not applicable.

Consent to participate Not applicable.

Consent for publication Not applicable
Open Access This article is licensed under a Creative Commons Attribution 4.0 International License, which permits use, sharing, adaptation, distribution and reproduction in any medium or format, as long as you give appropriate credit to the original author(s) and the source, provide a link to the Creative Commons licence, and indicate if changes were made. The images or other third party material in this article are included in the article's Creative Commons licence, unless indicated otherwise in a credit line to the material. If material is not included in the article's Creative Commons licence and your intended use is not permitted by statutory regulation or exceeds the permitted use, you will need to obtain permission directly from the copyright holder. To view a copy of this licence, visit http://creativecommons.org/licenses/by/4.0/.

\section{References}

1. European Medicines Agency. (2016, April 1). The use of patientreported outcome (PRO) measures in oncology studies. Appendix 2 to the guideline on the evaluation of anticancer medicinal products in man. EMA/CHMP/292464/2014.

2. McGrail, K., Bryan, S., \& Davis, J. (2011). Let's all go to the PROM: The case for routine patient-reported outcome measurement in Canadian healthcare. HealthcarePapers, 11(4), 8-18. discussion 55-58.

3. Fitzpatrick, R., Davey, C., Buxton, M. J., \& Jones, D. R. (1998). Evaluating patient-based outcome measures for use in clinical trials. Health Technology Assessment (Winchester, England), 2(14), $1-74$.

4. Aber, A., Poku, E., Phillips, P., Essat, M., Buckley Woods, H., Palfreyman, S., Kaltenthaler, E., Jones, G., \& Michaels, J. (2017). Systematic review of patient-reported outcome measures in patients with varicose veins. The British Journal of Surgery, 104(11), 1424-1432. https://doi.org/10.1002/bjs.10639

5. Poku, E., Aber, A., Phillips, P., Essat, M., Buckley Woods, H., Palfreyman, S., Kaltenthaler, E., Jones, G., \& Michaels, J. (2017). Systematic review assessing the measurement properties of patient-reported outcomes for venous leg ulcers. BJS open, 1(5), 138-147. https://doi.org/10.1002/bjs5.25

6. Hadi, M., Gibbons, E., \& Fitzpatrick, R. (2010). Structured Review of patient-reported outcome measures (PROMS) for colorectal cancer. Oxford University Press.

7. Gazala, S., Pelletier, J.-S., Storie, D., Johnson, J. A., Kutsogiannis, D. J., \& Bédard, E. L. R. (2013). A systematic review and meta-analysis to assess patient-reported outcomes after lung cancer surgery. The Scientific World Journal, 2013, 789625.

8. Straatman, J., van der Wielen, N., Joosten, P. J., Terwee, C. B., Cuesta, M. A., Jansma, E. P., \& van der Peet, D. L. (2016). Assessment of patient-reported outcome measures in the surgical treatment of patients with gastric cancer. Surgical Endoscopy, 30(5), 1920-1929.

9. Bosetti, C., Turati, F., \& La Vecchia, C. (2014). Hepatocellular carcinoma epidemiology. Best Practice \& Research Clinical Gastroenterology, 28(5), 753-770.

10. GLOBOCAN, WHO International Agency for Research in CAncer. (2019, 21 March). Global Cancer Observatory. Retrieved from http://gco.iarc.fr/

11. Sterne, J. A., Hernán, M. A., Reeves, B. C., Savović, J., Berkman, N. D., Viswanathan, M., Henry, D., Altman, D. G., Ansari, M. T., Boutron, I., Carpenter, J. R., \& Higgins, J. P. (2016). ROBINSI: a tool for assessing risk of bias in non-randomised studies of interventions. BMJ, 355, i4919.

12. Goossen, K., Tenckhoff, S., Probst, P., Grummich, K., Mihaljevic, A. L., Büchler, M. W., \& Diener, M. K. (2018). Optimal literature search for systematic reviews in surgery. Langenbeck's Archives of Surgery, 403(1), 119-129. 
13. Thomson Reuters. (2013). EndNote X7.7.

14. Terwee, C. B., Bot, S. D. M., de Boer, M. R., van der Windt, D. A. W. M., Knol, D. L., Dekker, J., Lex, M., \& de Vet, H. C. W. (2007). Quality criteria were proposed for measurement properties of health status questionnaires. Journal of Clinical Epidemiology, 60(1), 34-42.

15. FDA. (2009, December). Guidance for Industry: PatientReported Outcome Measures: Use in Medical Product Development to Support Labeling Claims. Retrieved from https://www. fda.gov/media/77832/download

16. Mokkink, L. B., Terwee, C. B., Patrick, D. L., Alonso, J., Stratford, P. W., Knol, D. L., Lex, M., \& de Vet, H. C. W. (2010). The COSMIN checklist for assessing the methodological quality of studies on measurement properties of health status measurement instruments: An international Delphi study. Quality of Life Research: An International Journal of Quality of Life Aspects of Treatment, Care and Rehabilitation, 19(4), 539-549.

17. Higgins, J. P. T., \& Green, S. (2011). Cochrane Handbook for Systematic Reviews of Interventions (5.1.0.). The Cochrane Collaboration. Retrieved from https://training.cochrane.org/cochr ane-handbook-systematic-reviews-interventions

18. Wells, G., Shea, B., O`Connell, D., Peterson, J., Welch, V., Losos, M., \& Tugwell, P. (2018, July 31). Newcastle-Ottawa quality assessment scale. Retrieved from http://www.ohri.ca/ programs/clinical_epidemiology/oxford.asp

19. The Nordic Cochrane Center, The Cochrane Collaboration. (2014). RevMan 5 software 5.3. Copenhagen.

20. Saleh, G., El-Sayed, M., Nashed, G. A., \& Gad, M. \& Abdelbary, M. S. (2013). Outcome after Hepatectomy versus percutaneous ablation for treatment of solitary hepatocellular carcinoma in Childs A cirrhotic patients. Departments of General Surgery \& Tropical Medicine, Benha University. Departments of General Surgery \& Tropical Medicine, Cairo University Hospital, Egypt.

21. Abou-Alfa, G. K., Meyer, T., Cheng, A.-L., El-Khoueiry, A. B., Rimassa, L., Ryoo, B.-Y., Cicin, I., Merle, P., Chen, Y., Park, J. W., Blanc, J. F., Bolondi, L., Klümpen, H.-J., Chan, S. L., Zagonel, V., Pressiani, T., Ryu, M.-H., Venook, A. P., Hessel, C., ... Kelley, R. K. (2018). Cabozantinib in patients with advanced and progressing hepatocellular carcinoma. The New England Journal of Medicine, 379(1), 54-63.

22. Aliberti, C., Benea, G., Tilli, M., \& Fiorentini, G. (2008). Chemoembolization (TACE) of unresectable intrahepatic cholangiocarcinoma with slow-release doxorubicin-eluting beads: Preliminary results. Cardiovascular and Interventional Radiology, 31(5), 883-888.

23. Barbare, J.-C., Bouché, O., Bonnetain, F., Dahan, L., LombardBohas, C., Faroux, R., Raoul, J. L., Cattan, S., Lemoine, A., Blanc, J. F., Bronowicki, J. P., \& Bedenne, L. (2009). Treatment of advanced hepatocellular carcinoma with long-acting octreotide: a phase III multicentre, randomised, double blind placebocontrolled study. European Journal of Cancer (Oxford, England), 45(10), 1788-1797.

24. Barbare, J.-C., Bouché, O., Bonnetain, F., Raoul, J.-L., Rougier, P., Abergel, A., Raoul, J. L., Cattan, S., Lemoine, A., Blanc, J. F., Bronowicki, J. P., Bedenne, L., \& Bedenne, L. (2005). Randomized controlled trial of tamoxifen in advanced hepatocellular carcinoma. Journal of Clinical Oncology: Official Journal of the American Society of Clinical Oncology, 23(19), 4338-4346.

25. Becker, G., Allgaier, H.-P., Olschewski, M., Zähringer, A., Blum, H. E., \& HECTOR Study Group. (2007). Long-acting octreotide versus placebo for treatment of advanced HCC: a randomized controlled double-blind study. Hepatology (Baltimore, Md), 45(1), 9-15.

26. Berr, F., Wiedmann, M., Tannapfel, A., Halm, U., Kohlhaw, K. R., Schmidt, F., Wittekind, C., Hauss, J., \& Mössner, J. (2000). Photodynamic therapy for advanced bile duct cancer: evidence for improved palliation and extended survival. Hepatology (Baltimore, Md), 31(2), 291-298.

27. Bianchi, G., Loguercio, C., Sgarbi, D., Abbiati, R., Brunetti, N., De Simone, T., Zoli, M., \& Marchesini, G. (2003). Reduced quality of life of patients with hepatocellular carcinoma. Digestive and Liver Disease: Official Journal of the Italian Society of Gastroenterology and the Italian Association for the Study of the Liver, 35(1), 46-54.

28. Blazeby, J. M., Currie, E., Zee, B. C. Y., Chie, W.-C., Poon, R. T., Garden, O. J., \& EORTC Quality of Life Group. (2004). Development of a questionnaire module to supplement the EORTC QLQ-C30 to assess quality of life in patients with hepatocellular carcinoma, the EORTC QLQ-HCC18. European Journal of Cancer, 40(16), 2439-2444.

29. Boulin, M., Hillon, P., Cercueil, J. P., Bonnetain, F., Dabakuyo, S., Minello, A., Jouve, J. L., Lepage, C., Bardou, M., Wendremaire, M., Guerard, P., Denys, A., Grandvuillemin, A., Chauffert, B., Bedenne, L., \& Guiu, B. (2014). Idarubicinloaded beads for chemoembolisation of hepatocellular carcinoma: results of the IDASPHERE phase I trial. Alimentary Pharmacology \& Therapeutics, 39(11), 1301-1313.

30. Brans, B., Lambert, B., De Beule, E., De Winter, F., Van Belle, S., Van Vlierberghe, H., De Hemptinne, B., \& Dierckx, R. A. (2002). Quality of life assessment in radionuclide therapy: A feasibility study of the EORTC QLQ-C30 questionnaire in palliative (131)I-lipiodol therapy. European Journal of Nuclear Medicine and Molecular Imaging, 29(10), 1374-1379.

31. Bruix, J., Qin, S., Merle, P., Granito, A., Huang, Y.-H., Bodoky, G., Pracht, M., Yokosuka, O., Rosmorduc, O., Breder, V., Gerolami, R., Masi, G., Ross, P. J., Song, T., Bronowicki, J.-P., Ollivier-Hourmand, I., Kudo, M., Cheng, A.-L., Llovet, J. M., ... Han, G. (2017). Regorafenib for patients with hepatocellular carcinoma who progressed on sorafenib treatment (RESORCE): a randomised, double-blind, placebo-controlled, phase 3 trial. Lancet (London, England), 389(10064), 56-66.

32. Brunocilla, P. R., Brunello, F., Carucci, P., Gaia, S., Rolle, E., Cantamessa, A., Castiglione, A., Ciccone, G., \& Rizzetto, M. (2013). Sorafenib in hepatocellular carcinoma: Prospective study on adverse events, quality of life, and related feasibility under daily conditions. Medical Oncology (Northwood, London, England), 30(1), 345.

33. Cao, W., Li, J., Hu, C., Shen, J., Liu, X., Xu, Y., \& Ye, Z. (2013). Symptom clusters and symptom interference of HCC patients undergoing TACE: A cross-sectional study in China. Supportive Care in Cancer: Official Journal of the Multinational Association of Supportive Care in Cancer, 21(2), 475-483.

34. Cebon, J., Findlay, M., Hargreaves, C., Stockler, M., Thompson, P., Boyer, M., Roberts, S., Poon, A., Scott, A. M., Kalff, V., Garas, G., \& Australasian Gastro-Intestinal Trials Group (AGITG) Ag0001H Investigators. (2006). Somatostatin receptor expression, tumour response, and quality of life in patients with advanced hepatocellular carcinoma treated with long-acting octreotide. British Journal of Cancer, 95(7), 853-861.

35. Chang-Chien, W.-Y., Lee, K.-T., \& Shi, H.-Y. (2014). P0132 A longitudinal prospective analysis of depression, anxiety, and quality of life in patients with hepatocellular carcinoma. European Journal of Cancer, 50, e46-e47.

36. Chay, W. Y., Tham, C. K., Toh, H. C., Lim, H. Y., Tan, C. K., Lim, C., Wang, W.-W., \& Choo, S.-P. (2017). Coriolus versicolor (Yunzhi) use as therapy in advanced hepatocellular carcinoma patients with poor liver function or who are unfit for standard therapy. Journal of Alternative and Complementary Medicine (New York, NY), 23(8), 648-652.

37. Huang, G., Chen, X., Lau, W. Y., Shen, F., Wang, R. Y., Yuan, S. X., Geng, W.-X., \& Zhou, W. P. (2014). Quality of life after 
surgical resection compared with radiofrequency ablation for small hepatocellular carcinomas. The British Journal of Surgery, 101(8), 1006-1015.

38. Cheng, A.-L., Kang, Y.-K., Chen, Z., Tsao, C.-J., Qin, S., Kim, J. S., Luo, R., Feng, J., Ye, S., Yang, T.-S., Xu, J., Sun, Y., Liang, H., Liu, J., Wang, J., Tak, W. Y., Pan, H., Burock, K., Zou, J., ... Guan, Z. (2009). Efficacy and safety of sorafenib in patients in the Asia-Pacific region with advanced hepatocellular carcinoma: a phase III randomised, double-blind, placebo-controlled trial. The Lancet Oncology, 10(1), 25-34.

39. Chen, Y., Jiang, T., Ru, W., Mao, A., \& Liu, Y. (2014). Objective tongue inspection on 142 liver cancer patients with dampheat syndrome. Chinese Journal of Integrative Medicine, 20(8), 585-590. https://doi.org/10.1007/s11655-014-1756-Z

40. Cheng, A.-L., Kang, Y.-K., Lin, D.-Y., Park, J.-W., Kudo, M., Qin, S., Chung, H.-C., Song, X., Xu, J., Poggi, G., Omata, M., Lowenthal, S. P., Lanzalone, S., Yang, L., Lechuga, M. J., \& Raymond, E. (2013). Sunitinib versus sorafenib in advanced hepatocellular cancer: results of a randomized phase III trial. Journal of Clinical Oncology: Official Journal of the American Society of Clinical Oncology, 31(32), 4067-4075.

41. Chie, W.-C., Blazeby, J. M., Hsiao, C.-F., Chiu, H.-C., Poon, R. T., Mikoshiba, N., Al-Kadhimi, G., Heaton, N., Calara, J., Collins, P., \& Caddick, K. (2012). International cross-cultural field validation of an European Organization for Research and Treatment of Cancer questionnaire module for patients with primary liver cancer, the European Organization for Research and Treatment of Cancer quality-of-life questionnaire HCC18. Hepatology (Baltimore, MD), 55(4), 1122-1129.

42. Chie, W.-C., Blazeby, J. M., Hsiao, C.-F., Chiu, H.-C., Poon, R. T., Mikoshiba, N., Al-Kadhim, G., Heaton, N., Calara, J., Collins, P., \& Caddick, K. (2017). Differences in health-related quality of life between European and Asian patients with hepatocellular carcinoma. Asia-Pacific Journal of Clinical Oncology, 13(5), e304-e311.

43. Chiu, C.-C., Lee, K.-T., Wang, J.-J., Sun, D.-P., Lee, H.-H., \& Shi, H.-Y. (2018). Health-Related quality of life before and after surgical resection of hepatocellular carcinoma: A prospective study. Asian Pacific Journal of Cancer Prevention: APJCP, 19(1), 65-72.

44. Chow, P. K. H., Tai, B.-C., Tan, C.-K., Machin, D., Win, K. M., Johnson, P. J., Soo, K. C., \& Asian-Pacific Hepatocellular Carcinoma Trials Group. (2002). High-dose tamoxifen in the treatment of inoperable hepatocellular carcinoma: A multicenter randomized controlled trial. Hepatology (Baltimore, Md), 36(5), $1221-1226$

45. Chow, P. K. H., Machin, D., Chen, Y., Zhang, X., Win, K.-M., Hoang, H.-H., Nguyen, B. D., Jin, M. Y., Lobo, R., Findlay, M., \& Lim, C. H. (2011). Randomised double-blind trial of megestrol acetate vs placebo in treatment-naive advanced hepatocellular carcinoma. British Journal of Cancer, 105(7), 945-952.

46. Chow, P. K. H., Poon, D. Y. H., Khin, M.-W., Singh, H., Han, H.-S., Goh, A. S. W., Choo, S.-P., Lai, H.-K., Lo, R. H. G., Tay, K.-H., Lim, T.-G., Gandhi, M., Tan, S.-B., Soo, K.-C., \& AsiaPacific Hepatocellular Carcinoma Trials Group. (2014). Multicenter phase II study of sequential radioembolization-sorafenib therapy for inoperable hepatocellular carcinoma. PloS One, 9(3), e90909.

47. Chung, M.-H., Wang, S.-Y., \& Lin, C.-C. (2017). Symptom clusters and impact of fatigue and sleep disturbance on symptom experiences of hepatoma patients in Taiwan. Cancer Nursing, 40(5), 403-411.

48. Cowawintaweewat, S., Manoromana, S., Sriplung, H., Khuhaprema, T., Tongtawe, P., Tapchaisri, P., \& Chaicumpa, W. (2006). Prognostic improvement of patients with advanced liver cancer after active hexose correlated compound (AHCC) treatment. Asian Pacific Journal of Allergy and Immunology, 24(1), 33-45.

49. Darwish Murad, S., Heimbach, J. K., Gores, G. J., Rosen, C. B., Benson, J. T., \& Kim, W. R. (2013). Excellent quality of life after liver transplantation for patients with perihilar cholangiocarcinoma who have undergone neoadjuvant chemoradiation. Liver Transplantation: Official Publication of the American Association for the Study of Liver Diseases and the International Liver Transplantation Society, 19(5), 521-528.

50. Dimitroulopoulos, D., Xinopoulos, D., Tsamakidis, K., Zisimopoulos, A., Andriotis, E., Markidou, S., Panagiotakos, D., Chrysohoou, C., Bazinis, A., \& Paraskevas, E. (2002). The role of sandostatin LAR in treating patients with advanced hepatocellular cancer. Hepato-Gastroenterology, 49(47), 1245-1250.

51. Dimitroulopoulos, D., Xinopoulos, D., Tsamakidis, K., Zisimopoulos, A., Andriotis, E., Panagiotakos, D., Fotopoulou, A., Chrysohoou, C., Bazinis, A., Daskalopoulou, D., \& Paraskevas, E. (2007). Long acting octreotide in the treatment of advanced hepatocellular cancer and overexpression of somatostatin receptors: randomized placebo-controlled trial. World Journal of Gastroenterology, 13(23), 3164-3170.

52. Doffoël, M., Bonnetain, F., Bouché, O., Vetter, D., Abergel, A., Fratté, S., Grangé, J. D., Stremsdoerfer, N., Blanchi, A., Bronowicki, J. P., Caroli-Bosc, F. X., \& Fédération Francophone de Cancérologie Digestive. (2008). Multicentre randomised phase III trial comparing Tamoxifen alone or with Transarterial Lipiodol Chemoembolisation for unresectable hepatocellular carcinoma in cirrhotic patients (Fédération Francophone de Cancérologie Digestive 9402). European Journal of Cancer (Oxford, England), 44(4), 528-538.

53. Dollinger, M. M., Lautenschlaeger, C., Lesske, J., Tannapfel, A., Wagner, A.-D., Schoppmeyer, K., Nehls, O., Welker, M. W., Wiest, R., Fleig, W. E., \& AIO Hepatobiliary Study Group. (2010). Thymostimulin versus placebo for palliative treatment of locally advanced or metastasised hepatocellular carcinoma: a phase III clinical trial. BMC Cancer, 10, 457.

54. Dumoulin, F. L., Gerhardt, T., Fuchs, S., Scheurlen, C., Neubrand, M., Layer, G., \& Sauerbruch, T. (2003). Phase II study of photodynamic therapy and metal stent as palliative treatment for nonresectable hilar cholangiocarcinoma. Gastrointestinal Endoscopy, 57(7), 860-867.

55. Eltawil, K. M., Berry, R., Abdolell, M., \& Molinari, M. (2012). Quality of life and survival analysis of patients undergoing transarterial chemoembolization for primary hepatic malignancies: a prospective cohort study. HPB: The Official Journal of the International Hepato Pancreato Biliary Association, 14(5), 341-350.

56. Fan, S.-Y., Eiser, C., Ho, M.-C., \& Lin, C.-Y. (2013). Healthrelated quality of life in patients with hepatocellular carcinoma: the mediation effects of illness perceptions and coping. PsychoOncology, 22(6), 1353-1360.

57. Gill, J., Baiceanu, A., Clark, P. J., Langford, A., Latiff, J., Yang, P.-M., Yoshida, E. M., \& Kanavos, P. (2018). Insights into the hepatocellular carcinoma patient journey: results of the first global quality of life survey. Future Oncology (London, England), 14(17), 1701-1710.

58. Gmür, A., Kolly, P., Knöpfli, M., \& Dufour, J.-F. (2018). FACTHep increases the accuracy of survival prediction in HCC patients when added to ECOG Performance Status. Liver International: Official Journal of the International Association for the Study of the Liver, 38(8), 1468-1474.

59. Hakim, J., Gudza, I., Kiire, C., Levy, L., Olweny, C. L. M., Clinch, J., \& Schipper, H. (1997). Quality of life (QOL) in hepatocellular carcinoma (HCC) in Zimbabwe. Presented at the AIDS and Supportive Care Symposium.

60. Hamdy, H., Barakat, E. M. F., Folly, E., \& Fouad, R. (2013). Impact of Hepatocellular Carcinoma on Health Related Quality 
of Life in Egyptian Patients : A Single Centre Study. Journal of the Egyptian Society of Parasitology, 240(1412), 1-12.

61. Hartrumpf, K. J., Marquardt, S., Werncke, T., Murray, T., Kirstein, M. M., Vogel, A., Wacker, F., \& Rodt, T. (2018). Quality of life in patients undergoing repetitive TACE for the treatment of intermediate stage HCC. Journal of Cancer Research and Clinical Oncology, 144(10), 1991-1999.

62. He, Q., Jiang, J. J., Jiang, Y. X., Wang, W. T., Yang, L., \& Liver Surgery Group. (2018). Health-related quality of life comparisons after radical therapy for early-stage hepatocellular carcinoma. Transplantation Proceedings, 50(5), 1470-1474.

63. Hebbar, M., Heurgue-Berlot, A., Boige, V., Le Malicot, K., Bernard-Chabert, B., Marcus, C., Dharancy, S., Sergent, G., Perarnau, J. M., Ehrhard, F., Ollivier-Hourmand, I., Vergniol, J., Michel, P., Edeline, J., Rinaldi, Y., Seitz, J. F., Lepage, C., $\&$ de Baere, T. (2015). Randomized phase $2 / 3$ trial of transcatheter arterial chemoembolization (TACE) plus sunitinib or placebo in patients with hepatocellular carcinoma (HCC) (PRODIGE 16/SATURNE study): Results of the Phase II part. European Journal of Cancer, 51, S434.

64. Heits, N., Meer, G., Bernsmeier, A., Guenther, R., Malchow, B., Kuechler, T., Becker, T., \& Braun, F. (2015). Mode of allocation and social demographic factors correlate with impaired quality of life after liver transplantation. Health and Quality of Life Outcomes, 13, 162.

65. Hinrichs, J. B., Hasdemir, D. B., Nordlohne, M., Schweitzer, N., Wacker, F., Vogel, A., Kirstein, M. M., Marquardt, S., \& Rodt, T. (2017). Health-related quality of life in patients with hepatocellular carcinoma treated with initial transarterial chemoembolization. Cardiovascular and Interventional Radiology, 40(10), 1559-1566.

66. Hoffmann, K., Glimm, H., Radeleff, B., Richter, G., Heining, C., Schenkel, I., Zahlten-Hinguranage, A., Schirrmacher, P., Schmidt, J., Büchler, M. W., Jaeger, D., \& Schemmer, P. (2008). Prospective, randomized, double-blind, multi-center, Phase III clinical study on transarterial chemoembolization (TACE) combined with Sorafenib versus TACE plus placebo in patients with hepatocellular cancer before liver transplantation - HeiLivCa [ISRCTN24081794]. BMC Cancer, 8, 349.

67. Hsu, W.-C., Tsai, A. C., Chan, S.-C., Wang, P.-M., \& Chung, N.-N. (2012). Mini-nutritional assessment predicts functional status and quality of life of patients with hepatocellular carcinoma in Taiwan. Nutrition and Cancer, 64(4), 543-549.

68. Jie, B., Qiu, Y., Feng, Z.-Z., \& Zhu, S.-N. (2016). Impact of disclosure of diagnosis and patient autonomy on quality of life and illness perceptions in Chinese patients with liver cancer. Psycho-Oncology, 25(8), 927-932.

69. Johnson, P. J., Qin, S., Park, J.-W., Poon, R. T. P., Raoul, J.-L., Philip, P. A., Hsu, C. H., Hu, T. H., Heo, J., Xu, J., Lu, L., \& Cheng, A.-L. (2013). Brivanib versus sorafenib as first-line therapy in patients with unresectable, advanced hepatocellular carcinoma: results from the randomized phase III BRISK-FL study. Journal of Clinical Oncology: Official Journal of the American Society of Clinical Oncology, 31(28), 3517-3524.

70. Kensinger, C. D., Feurer, I. D., O’Dell, H. W., LaNeve, D. C., Simmons, L., Pinson, C. W., \& Moore, D. E. (2016). Patientreported outcomes in liver transplant recipients with hepatocellular carcinoma. Clinical Transplantation, 30(9), 1036-1045.

71. Kirchhoff, T. D., Rudolph, K. L., Layer, G., Chavan, A., Greten, T. F., Rosenthal, H., Kubicka, S., Galanski, M., Manns, M. P., Schild, H., \& Gallkowski, U. (2006). Chemoocclusion vs chemoperfusion for treatment of advanced hepatocellular carcinoma: a randomised trial. European Journal of Surgical Oncology: The Journal of the European Society of Surgical Oncology and the British Association of Surgical Oncology, 32(2), 201-207.
72. Koeberle, D., Dufour, J.-F., Demeter, G., Li, Q., Ribi, K., Samaras, P., Saletti, P., Roth, A. D., Horber, D., Buehlmann, M., Wagner, A. D., Montemurro, M., Lakatos, G., Feilchenfeldt, J., Peck-Radosavljevic, M., Rauch, D., Tschanz, B., \& Bodoky, G. (2016). Sorafenib with or without everolimus in patients with advanced hepatocellular carcinoma (HCC): a randomized multicenter, multinational phase II trial (SAKK 77/08 and SASL 29). Annals of Oncology: Official Journal of the European Society for Medical Oncology, 27(5), 856-861.

73. Kolligs, F. T., Bilbao, J. I., Jakobs, T., Iñarrairaegui, M., Nagel, J. M., Rodriguez, M., Haug, A., D’Avola, D., de Winkel, M., Martinez-Cuesta, A., Trumm, C., \& Sangro, B. (2015). Pilot randomized trial of selective internal radiation therapy vs. chemoembolization in unresectable hepatocellular carcinoma. Liver International: Official Journal of the International Association for the Study of the Liver, 35(6), 1715-1721.

74. Kondo, Y., Yoshida, H., Tateishi, R., Shiina, S., Mine, N., Yamashiki, N., Sato, S., Kato, N., Kanai, F., Yanase, M., Yoshida, H., Akamatsu, M., Teratani, T., Kawabe, T., \& Omata, M. (2007). Health-related quality of life of chronic liver disease patients with and without hepatocellular carcinoma. Journal of Gastroenterology and Hepatology, 22(2), 197-203. https://doi.org/10. 1111/j.1440-1746.2006.04456.x

75. Kudo, M., Finn, R. S., Qin, S., Han, K.-H., Ikeda, K., Piscaglia, F., Baron, A., Park, J.-W., Han, G., Jassem, J., Blanc, J. F., Vogel, A., Komov, D., Evans, T. R. J., Lopez, C., Dutcus, C., Guo, M., Saito, K., Kraljevic, S., ... Cheng, A.-L. (2018). Lenvatinib versus sorafenib in first-line treatment of patients with unresectable hepatocellular carcinoma: a randomised phase 3 non-inferiority trial. Lancet (London, England), 391(10126), 1163-1173.

76. Kuroda, H., Ushio, A., Miyamoto, Y., Sawara, K., Oikawa, K., Kasai, K., Endo, R., Takikawa, Y., Kato, A., \& Suzuki, K. (2010). Effects of branched-chain amino acid-enriched nutrient for patients with hepatocellular carcinoma following radiofrequency ablation: a one-year prospective trial. Journal of Gastroenterology and Hepatology, 25(9), 1550-1555.

77. Lee, L.J.-H., Chen, C.-H., Yao, G., Chung, C.-W., Sheu, J.-C., Lee, P.-H., Tsai, Y.-J., \& Wang, J.-D. (2007). Quality of life in patients with hepatocellular carcinoma received surgical resection. Journal of Surgical Oncology, 95(1), 34-39.

78. Lei, J. Y., Yan, L. N., Wang, W. T., Zhu, J. Q., \& Li, D. J. (2016). Health-related quality of life and psychological distress in patients with early-stage hepatocellular carcinoma after hepatic resection or transplantation. Transplantation Proceedings, 48(6), 2107-2111.

79. Li, Y.-Y., Sha, W.-H., Zhou, Y.-J., \& Nie, Y.-Q. (2007). Short and long term efficacy of high intensity focused ultrasound therapy for advanced hepatocellular carcinoma. Journal of Gastroenterology and Hepatology, 22(12), 2148-2154.

80. Li, L., Mo, F. K., Chan, S. L., Hui, E. P., Tang, N. S., Koh, J., Leung, K. S. L., Poon, A. N. Y., Hui, J., Chu, C. M., Lee, K. F., Ma, B. B. Y., Lai, P. B. S., Chan, A. T. C., Yu, S. C. H., \& Yeo, W. (2017). Prognostic values of EORTC QLQ-C30 and QLQHCC18 index-scores in patients with hepatocellular carcinoma - clinical application of health-related quality-of-life data. $B M C$ Cancer, 17(1), 8

81. Liu, J., Wang, Y., Zhang, D., Liu, B., \& Ou, Q. (2012). Comparison of survival and quality of life of hepatectomy and thrombectomy using total hepatic vascular exclusion and chemotherapy alone in patients with hepatocellular carcinoma and tumor thrombi in the inferior vena cava and hepatic vein. European Journal of Gastroenterology \& Hepatology, 24(2), 186-194.

82. Llovet, J. M., Ricci, S., Mazzaferro, V., Hilgard, P., Gane, E., Blanc, J.-F., de Oliveira, A. C., Santoro, A., Raoul, J.-L., Forner, A., Schwartz, M., Porta, C., Zeuzem, S., Bolondi, L., Greten, T. F., Galle, P. R., Seitz, J.-F., Borbath, I., Häussinger, D., ... Bruix, 
J. (2008). Sorafenib in advanced hepatocellular carcinoma. The New England Journal of Medicine, 359(4), 378-390.

83. Lv, N., Kong, Y., Mu, L., Pan, T., Xie, Q., \& Zhao, M. (2016). Effect of perioperative parecoxib sodium on postoperative pain control for transcatheter arterial chemoembolization for inoperable hepatocellular carcinoma: a prospective randomized trial. European Radiology, 26(10), 3492-3499.

84. Manesis, E. K., Giannoulis, G., Zoumboulis, P., Vafiadou, I., \& Hadziyannis, S. J. (1995). Treatment of hepatocellular carcinoma with combined suppression and inhibition of sex hormones: a randomized, controlled trial. Hepatology (Baltimore, Md), 21(6), $1535-1542$

85. Meier, A., Yopp, A., Mok, H., Kandunoori, P., Tiro, J., \& Singal, A. G. (2015). Role functioning is associated with survival in patients with hepatocellular carcinoma. Quality of Life Research: An International Journal of Quality of Life Aspects of Treatment, Care and Rehabilitation, 24(7), 1669-1675.

86. Meyer, T., Kirkwood, A., Roughton, M., Beare, S., Tsochatzis, E., Yu, D., Davies, N., Williams, E., Pereira, S. P., Hochhauser, D., Mayer, A., Gillmore, R., O’Beirne, J., Patch, D., \& Burroughs, A. K. (2013). A randomised phase II/III trial of 3-weekly cisplatin-based sequential transarterial chemoembolisation vs embolisation alone for hepatocellular carcinoma. British Journal of Cancer, 108(6), 1252-1259.

87. Mihalache, F., Tantau, M., Diaconu, B., \& Acalovschi, M. (2010). Survival and quality of life of cholangiocarcinoma patients: a prospective study over a 4 year period. Journal of gastrointestinal and liver diseases: JGLD, 19(3), 285-290.

88. Mikoshiba, N., Tateishi, R., Tanaka, M., Sakai, T., Blazeby, J. M., Kokudo, N., Koike, K., \& Kazuma, K. (2012). Validation of the Japanese version of the EORTC hepatocellular carcinomaspecific quality of life questionnaire module (QLQ-HCC18). Health and Quality of Life Outcomes, 10, 58.

89. Mikoshiba, N., Miyashita, M., Sakai, T., Tateishi, R., \& Koike, K. (2013). Depressive symptoms after treatment in hepatocellular carcinoma survivors: prevalence, determinants, and impact on health-related quality of life. Psycho-Oncology, 22(10), 2347-2353.

90. Mise, Y., Satou, S., Ishizawa, T., Kaneko, J., Aoki, T., Hasegawa, K., Sugawara, Y., Makuuchi, M., \& Kokudo, N. (2014). Impact of surgery on quality of life in patients with hepatocellular carcinoma. World Journal of Surgery, 38(4), 958-967.

91. Montella, L., Addeo, R., Cennamo, G., Vincenzi, B., Palmieri, R., Sperlongano, P., Sperlongano, R., Iodice, P., Russo, P., \& Del Prete, S. (2013). Sorafenib in elderly patients with advanced hepatocellular carcinoma: a case series. Oncology, 84(5), 265-272.

92. Müller, C., Schöniger-Hekele, M., Schernthaner, R., Renner, B., Peck-Radosavljevic, M., Brichta, A., Wrba, F., Posch, M., Bauer, P., Ferenci, P., \& Gangl, A. (2008). Percutaneous ethanol instillation therapy for hepatocellular carcinoma - a randomized controlled trial. Wiener Klinische Wochenschrift, 120(19-20), 608-618.

93. Nojiri, S., Fujiwara, K., Shinkai, N., Iio, E., \& Joh, T. (2017). Effects of branched-chain amino acid supplementation after radiofrequency ablation for hepatocellular carcinoma: A randomized trial. Nutrition, 33, 20-27.

94. Nowak, A. K., Cebon, J., Hargreaves, C., Dhillon, H., Findlay, M., Gebski, V., \& Stockler, M. R. (2008). Assessment of healthrelated quality of life and patient benefit as outcome measures for clinical trials in hepatocellular carcinoma. Asia-Pacific Journal of Clinical Oncology, 4(1), 55-67.

95. Nugent, F. W., Qamar, A., Stuart, K. E., Galuski, K., Flacke, S., Molgaard, C., Gordon, F., Iqbal, S., Hunter, K. U., Hartnett, E., \& Gunturu, K. (2017). A randomized phase II study of individualized stereotactic body radiation therapy (SBRT) versus transarterial chemoembolization (TACE) with DEBDOX beads as a bridge to transplant in hepatocellular carcinoma (HCC). Journal of Clinical Oncology, 35(4_suppl), 223-223.

96. Ortner, M. E. J., Caca, K., Berr, F., Liebetruth, J., Mansmann, U., Huster, D., Voderholzer, W., Schachschal, G., Mössner, J., \& Lochs, H. (2003). Successful photodynamic therapy for nonresectable cholangiocarcinoma: a randomized prospective study. Gastroenterology, 125(5), 1355-1363s.

97. Otegbayo, J. A., Yakubu, A., Akere, A., Igetei, R., \& Aje, A. O. (2005). Quality of life among primary liver cell carcinoma patients in Ibadan, Nigeria. African Journal of Medicine and Medical Sciences, 34(1), 51-54.

98. Palmieri, V. O., Santovito, D., Margari, F., Lozupone, M., Minerva, F., Di Gennaro, C., Todarello, O., \& Palasciano, G. (2015). Psychopathological profile and health-related quality of life (HRQOL) in patients with hepatocellular carcinoma (HCC) and cirrhosis. Clinical and Experimental Medicine, 15(1), 65-72.

99. Poon, R. T., Fan, S. T., Yu, W. C., Lam, B. K., Chan, F. Y., \& Wong, J. (2001). A prospective longitudinal study of quality of life after resection of hepatocellular carcinoma. Archives of Surgery (Chicago, IL), 136(6), 693-699.

100. Poon, R.T.-P., Yu, W.-C., Fan, S.-T., \& Wong, J. (2004). Longterm oral branched chain amino acids in patients undergoing chemoembolization for hepatocellular carcinoma: a randomized trial. Alimentary Pharmacology \& Therapeutics, 19(7), 779-788.

101. Qiao, C.-X., Zhai, X.-F., Ling, C.-Q., Lang, Q.-B., Dong, H.-J., Liu, Q., \& Li, M.-D. (2012). Health-related quality of life evaluated by tumor node metastasis staging system in patients with hepatocellular carcinoma. World Journal of Gastroenterology, 18(21), 2689-2694.

102. Ryu, E., Kim, K., Cho, M. S., Kwon, I. G., Kim, H. S., \& Fu, M. R. (2010). Symptom clusters and quality of life in Korean patients with hepatocellular carcinoma. Cancer Nursing, 33(1), 3-10.

103. Salem, R., Gilbertsen, M., Butt, Z., Memon, K., Vouche, M., Hickey, R., Baker, T., Abecassis, M. M., Atassi, R., Riaz, A., Cella, D., Burns, J. L., Ganger, D., Benson, Al. B., Mulcahy, M. F., Kulik, L., \& Lewandowski, R. (2013). Increased quality of life among hepatocellular carcinoma patients treated with radioembolization, compared with chemoembolization. Clinical Gastroenterology and Hepatology: The Official Clinical Practice Journal of the American Gastroenterological Association, 11(10), 1358-1365.

104. Shomura, M., Kagawa, T., Okabe, H., Shiraishi, K., Hirose, S., Arase, Y., Takahira, K., \& Mine, T. (2016). Longitudinal alterations in health-related quality of life and its impact on the clinical course of patients with advanced hepatocellular carcinoma receiving sorafenib treatment. BMC Cancer, 16(1), 878.

105. Shun, S.-C., Chiou, J.-F., Lai, Y.-H., Yu, P.-J., Wei, L.-L., Tsai, J.-T., Kao, C.-Y., \& Hsiao, Y.-L. (2008). Changes in quality of life and its related factors in liver cancer patients receiving stereotactic radiation therapy. Supportive Care in Cancer: Official Journal of the Multinational Association of Supportive Care in Cancer, 16(9), 1059-1065.

106. Shun, S.-C., Chen, C.-H., Sheu, J.-C., Liang, J.-D., Yang, J.-C., \& Lai, Y.-H. (2012). Quality of life and its associated factors in patients with hepatocellular carcinoma receiving one course of transarterial chemoembolization treatment: a longitudinal study. The Oncologist, 17(5), 732-739.

107. Somjaivong, B., Thanasilp, S., Preechawong, S., \& Sloan, R. (2011). The influence of symptoms, social support, uncertainty, and coping on health-related quality of life among cholangiocarcinoma patients in northeast Thailand. Cancer Nursing, 34(6), 434-442. 
108. Steel, J., Baum, A., \& Carr, B. (2004). Quality of life in patients diagnosed with primary hepatocellular carcinoma: hepatic arterial infusion of Cisplatin versus 90-Yttrium microspheres (Therasphere). Psycho-Oncology, 13(2), 73-79.

109. Steel, J., Hess, S. A., Tunke, L., Chopra, K., \& Carr, B. I. (2005). Sexual functioning in patients with hepatocellular carcinoma. Cancer, 104(10), 2234-2243.

110. Steel, J. L., Geller, D. A., \& Carr, B. I. (2005). Proxy ratings of health related quality of life in patients with hepatocellular carcinoma. Quality of Life Research: An International Journal of Quality of Life Aspects of Treatment, Care and Rehabilitation, 14(4), 1025-1033.

111. Steel, J. L., Chopra, K., Olek, M. C., \& Carr, B. I. (2007). Healthrelated quality of life: Hepatocellular carcinoma, chronic liver disease, and the general population. Quality of Life Research: An International Journal of Quality of Life Aspects of Treatment, Care and Rehabilitation, 16(2), 203-215.

112. Steel, J. L., Geller, D. A., Robinson, T. L., Savkova, A. Y., Brower, D. S., Marsh, J. W., \& Tsung, A. (2014). Health-related quality of life as a prognostic factor in patients with advanced cancer. Cancer, 120(23), 3717-3721.

113. Sternby Eilard, M., Hagström, H., Mortensen, K. E., Wilsgaard, T., Vagnildhaug, O. M., Dajani, O., Stål, P., \& Rizell, M. (2018). Quality of life as a prognostic factor for survival in hepatocellular carcinoma. Liver International: Official Journal of the International Association for the Study of the Liver, 38(5), 885-894.

114. Tanabe, G., Ueno, S., Maemura, M., Kihara, K., Aoki, D., Yoshidome, S., Ogura, Y., Hamanoue, M., Ogura, Y., Hamanoue, M., \& Aikou, T. (2001). Favorable quality of life after repeat hepatic resection for recurrent hepatocellular carcinoma. Hepato-Gastroenterology, 48(38), 506-510.

115. Tian, H., Li, H., Wang, B., Liang, G., Huang, X., Huang, Z., Lang, Mp., Zhang, Yp., Chen, X. Z., \& Chen, Y. (2010). Treatment of middle/late stage primary hepatic carcinoma by Chinese medicine comprehensive therapy: A prospective randomized controlled study. Chinese Journal of Integrative Medicine, 16(2), 102-108.

116. Toro, A., Pulvirenti, E., Palermo, F., \& Di Carlo, I. (2012). Health-related quality of life in patients with hepatocellular carcinoma after hepatic resection, transcatheter arterial chemoembolization, radiofrequency ablation or no treatment. Surgical Oncology, 21(1), e23-30.

117. Park, D. H., Lee, S. S., Park, S. E., Lee, J. L., Choi, J. H., Choi, H. J., Jang, J. W., Kim, H. J., Eum, J. B., Seo, D. W., \& Lee, J. B. (2014). Randomised phase II trial of photodynamic therapy plus oral fluoropyrimidine, S-1, versus photodynamic therapy alone for unresectable hilar cholangiocarcinoma. European Journal of Cancer (Oxford, England), 50(7), 1259-1268.

118. Treiber, G., Röcken, C., Wex, T., \& Malfertheiner, P. (2007). Octreotide alone or in combination with rofecoxib as palliative treatment for advanced hepatocellular cancer. Zeitschrift Fur Gastroenterologie, 45(5), 369-377.

119. Ueno, S., Tanabe, G., Nuruki, K., Yoshidome, S., Kubo, F., Kihara, K., Aoki, D., \& Aikou, T. (2002). Quality of life after hepatectomy in patients with hepatocellular carcinoma: implication of change in hepatic protein synthesis. Hepato-Gastroenterology, 49(44), 492-496.

120. Wan, C., Fang, J., Yang, Z., Zhang, C., Luo, J., Meng, Q., \& Jiang, D. (2010). Development and validation of a quality of life instrument for patients with liver cancer QOL-LC. American Journal of Clinical Oncology, 33(5), 448-455.

121. Vilgrain, V., Pereira, H., Assenat, E., Guiu, B., Ilonca, A. D., Pageaux, G.-P., Sibert, A., Bouattour, M., Lebtahi, R., Allaham, W., Barraud, H., Laurent, V., Mathias, E., Bronowicki, J.-P., Tasu, J.-P., Perdrisot, R., Silvain, C., Gerolami, R., Mundler, O., ... Marthey, L. (2017). Efficacy and safety of selective internal radiotherapy with yttrium-90 resin microspheres compared with sorafenib in locally advanced and inoperable hepatocellular carcinoma (SARAH): an open-label randomised controlled phase 3 trial. The Lancet. Oncology, 18(12), 1624-1636.

122. Wang, Y.-B., Chen, M.-H., Yan, K., Yang, W., Dai, Y., \& Yin, S.-S. (2007). Quality of life after radiofrequency ablation combined with transcatheter arterial chemoembolization for hepatocellular carcinoma: Comparison with transcatheter arterial chemoembolization alone. Quality of Life Research: An International Journal of Quality of Life Aspects of Treatment, Care and Rehabilitation, 16(3), 389-397.

123. Wang, L., Wang, Y., Tang, L., Feng, C., Liu, X., Zhang, R., \& Liu, D. (2012). Quality of life and the relevant factors in patients with chronic hepatitis B. Hepato-Gastroenterology, 59(116), 1036-1042.

124. Wang, Y., Yang, X., Yu, Y., Xu, Z., Sun, Y., Liu, H., Sha, B., Li, L., Ding, N., Li, Z., Jin, H., \& Qian, Q. (2018). Immunotherapy of patient with hepatocellular carcinoma using cytotoxic T lymphocytes ex vivo activated with tumor antigen-pulsed dendritic cells. Journal of Cancer, 9(2), 275-287.

125. Wible, B. C., Rilling, W. S., Drescher, P., Hieb, R. A., Saeian, K., Frangakis, C., Chen, Y., Eastwood, D., \& Kim, H. S. (2010). Longitudinal quality of life assessment of patients with hepatocellular carcinoma after primary transarterial chemoembolization. Journal of vascular and interventional radiology: JVIR, 21(7), 1024-1030.

126. Wiedmann, M., Berr, F., Schiefke, I., Witzigmann, H., Kohlhaw, K., Mössner, J., \& Caca, K. (2004). Photodynamic therapy in patients with non-resectable hilar cholangiocarcinoma: 5-year follow-up of a prospective phase II study. Gastrointestinal Endoscopy, 60(1), 68-75.

127. Woradet, S., Promthet, S., Songserm, N., \& Parkin, D. M. (2015). Factors affecting health-related quality of life in patients with cholangiocarcinoma in the northeastern region of Thailand. Cancer Nursing, 38(6), E46-51.

128. Xie, Z. R., Luo, Y. L., Xiao, F. M., Liu, Q., \& Ma, Y. (2015). Health-related quality of life of patients with intermediate hepatocellular carcinoma after liver resection or transcatheter arterial chemoembolization. Asian Pacific journal of cancer prevention: APJCP, 16(10), 4451-4456.

129. Xing, M., Webber, G., Prajapati, H. J., Chen, Z., El-Rayes, B., Spivey, J. R., Pillai, A. A., \& Kim, H. S. (2015). Preservation of quality of life with doxorubicin drug-eluting bead transarterial chemoembolization for unresectable hepatocellular carcinoma: Longitudinal prospective study. Journal of Gastroenterology and Hepatology, 30(7), 1167-1174.

130. Xing, M., Kokabi, N., Camacho, J. C., \& Kim, H. S. (2018). Prospective longitudinal quality of life and survival outcomes in patients with advanced infiltrative hepatocellular carcinoma and portal vein thrombosis treated with Yttrium-90 radioembolization. BMC Cancer, 18(1), 75.

131. Xu, L., Wang, S., Zhuang, L., Lin, J., Chen, H., Zhu, X., Bei, W., Zhao, Q., Wu, H., \& Meng, Z. (2016). Jian Pi Li Qi decoction alleviated postembolization syndrome following transcatheter arterial chemoembolization for hepatocellular carcinoma: A randomized Double-Blind. Integrative Cancer Therapies, 15(3), 349-357.

132. Yang, Z., Wan, C., Li, W., Cun, Y., Meng, Q., Ding, Y., \& Chen, P. (2015). Development and validation of the simplified chinese version of EORTC QLQ-HCC18 for patients with hepatocellular carcinoma. Cancer Investigation, 33(8), 340-346.

133. Yang, B., You, X., Yuan, M. L., Qin, T. Q., Duan, L. J., He, J., Fei, Z. J., Zhou, X., Zan, R. Y., \& Liao, Z. Y. (2016). Transarterial Ethanol Ablation Combined with Transarterial Chemoembolization for Hepatocellular Carcinoma with Portal Vein Tumor Thrombus. Hepatitis Monthly, 16(8), e37584. 
134. Yau, T., Cheng, P. N., Chan, P., Chen, L., Yuen, J., Pang, R., Fan, S. T., Wheatley, D. N., Pang, R., \& Poon, R. T. (2015). Preliminary efficacy, safety, pharmacokinetics, pharmacodynamics and quality of life study of pegylated recombinant human arginase 1 in patients with advanced hepatocellular carcinoma. Investigational New Drugs, 33(2), 496-504.

135. Ye, X., Lu, D., Chen, X., Li, S., Chen, Y., \& Deng, L. (2016). A Multicenter, Randomized, Double-Blind, Placebo-Controlled Trial of Shuangbai San for Treating Primary Liver Cancer Patients With Cancer Pain. Journal of Pain and Symptom Management, 51(6), 979-986.

136. Yen, Y., So, S., Rose, M., Saif, M. W., Chu, E., Liu, S.-H., Foo, A., Jiang, Z., Su, T., \& Cheng, Y.-C. (2009). Phase I/II study of PHY906/capecitabine in advanced hepatocellular carcinoma. Anticancer Research, 29(10), 4083-4092.

137. Zhang, Y., Fan, W., Zhu, K., Lu, L., Fu, S., Huang, J., Wang, Y., Yang, J., Huang, Y., Yao, W., \& Li, J. (2015). Sorafenib continuation or discontinuation in patients with unresectable hepatocellular carcinoma after a complete response. Oncotarget, 6(27), 24550-24559.

138. Zheng, W., Wu, J., Xiao, J.-R., \& Guo, Q. (2013). Survival and health-related quality of life in patients with spinal metastases originated from primary hepatocellular carcinoma. Journal of Evidence-Based Medicine, 6(2), 81-89.

139. Zhu, A. X., Kudo, M., Assenat, E., Cattan, S., Kang, Y.-K., Lim, H. Y., Poon, R. T. P., Blanc, J.-F., Vogel, A., Chen, C.-L., Dorval, E., Peck-Radosavljevic, M., Santoro, A., Daniele, B., Furuse, J., Jappe, A., Perraud, K., Anak, O., Sellami, D. B., \& Chen, L.-T. (2014). Effect of everolimus on survival in advanced hepatocellular carcinoma after failure of sorafenib: The EVOLVE-1 randomized clinical trial. JAMA, 312(1), 57-67.

140. Zhu, A. X., Park, J. O., Ryoo, B.-Y., Yen, C.-J., Poon, R., Pastorelli, D., Blanc, J.-F., Chung, H. C., Baron, A. D., Pfiffer, T. E. F., Okusaka, T., Kubackova, K., Trojan, J., Sastre, J., Chau, I., Chang, S.-C., Abada, P. B., Yang, L., Schwartz, J. D., \& Kudo, M. (2015). Ramucirumab versus placebo as second-line treatment in patients with advanced hepatocellular carcinoma following first-line therapy with sorafenib $(\mathrm{REACH})$ : A randomised, double-blind, multicentre, phase 3 trial. The Lancet Oncology, 16(7), 859-870.

141. Unal, G., de Boer, J. B., Borsboom, G. J., Brouwer, J. T., EssinkBot, M., \& de Man, R. A. (2001). A psychometric comparison of health-related quality of life measures in chronic liver disease. Journal of Clinical Epidemiology, 54(6), 587-596.

142. Yount, S. E., Cella, D., Webster, K., Heffernan, N., Chang, C.-H., Odom, L., \& van Gool, R. (2002). Assessment of patientreported clinical outcome in pancreatic and other hepatobiliary cancers: The FACT Hepatobiliary Symptom Index. Journal of Pain and Symptom Management, 24(1), 32-44.

143. Chie, W.-C., Yu, F., Li, M., Baccaglini, L., Blazeby, J. M., Hsiao, C.-F., Chiu, H.-C., Poon, R. T., Mikoshiba, N., Al-Kadhimi, G., Heaton, N., Calara, J., Collins, P., Caddick, K., Costantini, A., Vilgrain, V., \& Chiang, C. (2015). Quality of life changes in patients undergoing treatment for hepatocellular carcinoma. Quality of Life Research: An International Journal of Quality of Life Aspects of Treatment, Care and Rehabilitation, 24(10), 2499-2506.

144. Heffernan, N., Cella, D., Webster, K., Odom, L., Martone, M., Passik, S., Bookbinder, M., Fong, Y., Jarnagin, W., \& Blumgart, L. (2002). Measuring health-related quality of life in patients with hepatobiliary cancers: The functional assessment of cancer therapy-hepatobiliary questionnaire. Journal of Clinical Oncology: Official Journal of the American Society of Clinical Oncology, 20(9), 2229-2239.

145. Zhu, Z., Lang, Q., Chen, Z., Li, D., \& Ling, C. (2008). Evaluation of Chinese version of the Functional Assessment of Cancer
Therapy-Hepatobiliary questionnaire. Journal of Chinese Integrative Medicine, 6(4), 341-345. https://doi.org/10.3736/jcim2 0080403

146. Kim, W. R., Lindor, K. D., Malinchoc, M., Petz, J. L., Jorgensen, R., \& Dickson, E. R. (2000). Reliability and validity of the NIDDK-QA instrument in the assessment of quality of life in ambulatory patients with cholestatic liver disease. Hepatology (Baltimore, Md), 32(5), 924-929. https://doi.org/10.1053/jhep. 2000.19067

147. Steel, J. L., Eton, D. T., Cella, D., Olek, M. C., \& Carr, B. I. (2006). Clinically meaningful changes in health-related quality of life in patients diagnosed with hepatobiliary carcinoma. Annals of Oncology, 17(2), 304-312.

148. Bayliss, M. S., Gandek, B., Bungay, K. M., Sugano, D., Hsu, M. A., \& Ware, J. E. (1998). A questionnaire to assess the generic and disease-specific health outcomes of patients with chronic hepatitis C. Quality of Life Research: An International Journal of Quality of Life Aspects of Treatment, Care and Rehabilitation, 7(1), 39-55. https://doi.org/10.1023/a:10088 84805251

149. Zhou, K. N., Zhang, M., Wu, Q., Ji, Z. H., Zhang, X. M., \& Zhuang, G. H. (2013). Reliability, validity and sensitivity of the Chinese (simple) short form 36 health survey version 2 (SF$36 \mathrm{v} 2)$ in patients with chronic hepatitis B. Journal of Viral Hepatitis, 20(4), e47-55. https://doi.org/10.1111/jvh.12030

150. Casanovas, T., Jané, L., Herdman, M., Casado, A., Garcia, B., Prat, B., \& Fabregat, J. (2010). Assessing outcomes in liver disease patients: reliability and validity of the Spanish version of the Liver Disease Quality of Life Questionnaire (LDQOL 1.0). Value in Health: The Journal of the International Society for Pharmacoeconomics and Outcomes Research, 13(4), 455-462. https://doi.org/10.1111/j.1524-4733.2009.00688.x

151. Lin, C.-Y., Hwang, J.-S., Wang, W.-C., Lai, W.-W., Su, W.-C., Wu, T.-Y., Yao, G., \& Wang, J.-D. (2019). Psychometric evaluation of the WHOQOL-BREF, Taiwan version, across five kinds of Taiwanese cancer survivors: Rasch analysis and confirmatory factor analysis. Journal of the Formosan Medical Association, 118(1 Pt 2), 215-222. https://doi.org/10.1016/j.jfma.2018.03.018

152. Cella, D. F., Tulsky, D. S., Gray, G., Sarafian, B., Linn, E., Bonomi, A., Silberman, M., Yellen, S. B., Winicour, P., \& Brannon, J. (1993). The Functional Assessment of Cancer Therapy scale: development and validation of the general measure. Journal of Clinical Oncology: Official Journal of the American Society of Clinical Oncology, 11(3), 570-579.

153. Chau, I., Peck-Radosavljevic, M., Borg, C., Malfertheiner, P., Seitz, J. F., Park, J. O., Ryoo, B. Y., Yen, C.-J., Kudo, M., Poon, R., Pastorelli, D., Blanc, J.-F., Chung, H. C., Baron, A. D., Okusaka, T., Bowman, L., Cui, Z. L., Girvan, A. C., Abada, P. B., ... Zhu, A. X. (2017). Ramucirumab as second-line treatment in patients with advanced hepatocellular carcinoma following first-line therapy with sorafenib: Patient-focused outcome results from the randomised phase III REACH study. European Journal of Cancer (Oxford, England), 81, 17-25.

154. ISOQOL. (n.d.). International Society for Quality of Life Research. Retrieved 21 November 2020, from https://www.isoqol.org/what-is-qol/

155. Schipper, H., Clinch, J. J., \& Olweny, C. L. M. (1996). Quality of life studies: definitions and conceptual issues. In B. Spilker (Ed.), Quality of life and pharmacoeconomics in clinical trials (pp. 11-23). Lippincott-Raven Publishers.

156. Ware, J. E., Snow, K. K., Kosinski, M., Gandek, B., \& Institute, N. E. M. C. H. H. (1993). SF-36 health survey: manual and interpretation guide. The Health Institute.

157. Aaronson, N. K., Ahmedzai, S., Bergman, B., Bullinger, M., Cull, A., Duez, N. J., Filiberti, A., Flechtner, H., Fleishman, S. B., Haes, J. C. J. M., Kaasa, S., Klee, M., Osoba, D., Razavi, D., 
Rofe, P. B., Schraub, S., Sneeuw, K., Sullivan, M., Takeda, F., ... de. . (1993). The European Organization for Research and Treatment of Cancer QLQ-C30: a quality-of-life instrument for use in international clinical trials in oncology. Journal of the National Cancer Institute, 85(5), 365-376.

158. EuroQol. (2017, February 17.). EQ-5D. Retrieved from http:// www.euroqol.org/

159. Basch, E., Abernethy, A. P., Mullins, C. D., Reeve, B. B., Smith, M. L., Coons, S. J., Sloan, J., Wenzel, K., Chauhan, C., Eppard, W., Frank, E. S., Lipscomb, J., Raymond, S. A., Spencer, M., \& Tunis, S. (2012). Recommendations for incorporating patient-reported outcomes into clinical comparative effectiveness research in adult oncology. Journal of Clinical Oncology: Official Journal of the American Society of Clinical Oncology, 30(34), 4249-4255.

160. Staquet, M., Berzon, R., Osoba, D., \& Machin, D. (1996). Guidelines for reporting results of quality of life assessments in clinical trials. Quality of Life Research: An International Journal of Quality of Life Aspects of Treatment, Care and Rehabilitation, 5(5), 496-502.

161. Brundage, M., Blazeby, J., Revicki, D., Bass, B., de Vet, H., Duffy, H., Efficace, F., King, M., Lam, C. L. K., Moher, D., Scott, J., Sloan, J., Snyder, C., Yount, S., \& Calvert, M. (2013).
Patient-reported outcomes in randomized clinical trials: development of ISOQOL reporting standards. Quality of Life Research. https://doi.org/10.1007/s11136-012-0252-1

162. Calvert, M., Blazeby, J., Altman, D. G., Revicki, D. A., Moher, D., Brundage, M. D., \& CONSORT PRO Group. (2013). Reporting of patient-reported outcomes in randomized trials: the CONSORT PRO extension. JAMA, 309(8), 814-822.

163. Guiu, B., et al. (2018). Intra-arterial idarubicin_lipiodol without embolisation in hepatocellular carcinoma: The LIDA-B phase I trial. J. Hepatol., 68, 1163-1171.

164. Lee, E. Relationships among depressive symptoms, spiritual well-being, and quality of life in primary liver cancer patients in Korea. (2012). PhD thesis, May 2012, Case Western Reserve University, accessed on 07/12/2021 through:https://www.proqu est.com/openview/118a458bcbb7863ae3f345493992f852/1? pqorigsite $=$ gscholar $\& \mathrm{cbl}=18750$

Publisher's Note Springer Nature remains neutral with regard to jurisdictional claims in published maps and institutional affiliations. 